\title{
The effects of different additives on the dielectric relaxation and the dynamic mechanical properties of urethane dimethacrylate
}

\author{
N. M. MOHSEN, R. G. CRAIG \& F. E. FILISKO School of Dentistry, The University of Michigan, Ann Arbor, MI, \\ U.S.A
}

SUMMARY The polymer-filler interaction of a dental composite was examined by dielectric measurements to determine how a non-compatible inorganic phase modifies the molecular behaviour of the polymer chains and how modification of this phase by silanation can affect these molecular behaviours. Urethane dimethacrylate (UDMA) monomer and zirconia-silica (ZS) powder were used as organic and inorganic phases, respectively. 3-Acryloxypropyltrimethoxysilane (MAPM) and 4aminobutyltriethoxysilane (ABTE) were used as silanating coupling agents. The components of the composite were mixed in different ratios after treating the filler with from 0 to 30 times the minimum uniform coverage with the silane, then the composite was made into thin films. The dielectric spectra of five replicas for each filler-monomer ratio were measured, and three replicas were measured for each silane and for each amount of silane used to treat the filler. Increasing the filler concentration in the composites decreased the intensity of $\operatorname{Tan}(\delta)_{\varepsilon}$ for the $\alpha$ - and $\beta$-relaxations, where the $\beta$-relaxations also became broader and the $\alpha$-relaxations were totally obstructed. The $\alpha$-relaxations were shifted to higher temperatures, while the $\beta$-relaxations were shifted to lower temperatures. Filler treatment with small amounts of MAPM shifted the $\alpha$-relaxations to higher temperatures; they were shifted back to lower temperatures when the filler was treated with large amounts of silane. Filler treatment with large amounts of ABTE (30-fold) caused an extra peak to emerge in the high-temperature region. It can be concluded that increasing filler concentration restricts the mobility of the main chains and decreases the thickness of the surface layer, while allowing more movement of the local chains. Filler treatment with MAPM was shown to be a compatible coupling agent with the ZS and the UDMA systems. Such compatibility was observed through the effectiveness of the chemical linkage of the silane to the filler and the polymer without forming a separate inter-phase. Filler treatment with ABTE was shown to be an incompatible coupling agent for the ZS-filled UDMA system. The incompatibility was observed by the occurrence of a new peak that characterizes an inter-phase.

\section{Introduction}

Polymeric-based composites, including medical and dental composites, are multi-component systems that include pure polymers, stabilizers, plasticizers, dyes, pigments, organic and inorganic fillers. These components are usually incorporated to change and improve specific macroscopic properties, such as toughness, fatigue, hardness, friction and electrical insulation. Ac- cording to Hedvig (1977), these additive components may be divided into two main physical groups: compatible and incompatible groups. In the first group, the additives do not form a separate phase in the polymer compound, which results, to some degree, in a homogeneous compound (examples are plasticizers). In the second group, the additives form a separate phase, which results in a heterogeneous system (examples are 
fillers, pigments and water inclusions) if the solubility is exceeded.

As an incompatible additive, fillers play an important role in determining and regulating properties of composites, such as strength, modulus, colour and durability. A wide variety of inorganic-filled polymers have been characterized quite extensively in terms of particle sizes, structure, density and porosity of the filler. However, what is even more difficult to characterize is the property called polymer-filler interaction. This term was broadly described by Ziegel $\&$ Romanov (1973), which includes the interfacial forces between the filler and the polymer, the orientation of the polymer in the vicinity of the surface of the filler, the formation of an inter-phase, and other physico-chemical phenomena. Without knowledge of these interactions, it is difficult to select fillers for a particular polymer system and to determine the appropriate conditions for their processing.

The polymer-filler interaction has been a topic for many researchers. It has been shown by Ziegel $\&$ Romanov (1973) that the effect of filler incorporation as an incompatible separate phase can often interfere with the curing mechanism, either by altering the chemical environment, participating in side reactions or simply by removing active ingredients from the organic matrix by adsorption onto the filler surface. Also, filler concentration, as well as type and size, as shown by Gordon, Howard \& Shanks (1982), are statistically significant factors, which can affect the glass transition temperature $\left(T_{\mathrm{g}}\right)$ in the silica-poly(vinyl chloride-co-vinyl acetate) system. Filler presence, as shown by Peyser \& Bascom (1977), changes the extent and direction of the change in $T_{\mathrm{g}}$ with different thermal histories in polystyrene-silica and epoxy-rubber systems. Further, composite materials were shown by Whiting \& Jacobsen (1980) to have higher elastic moduli and lower damping compared with unfilled resin for a range of polymeric restorative materials. In addition, the presence of Aerosil and Teflon fillers in polystyrene and poly(methylmethacrylate) (PMMA) was shown by Lipatov (1977) to reflect changes of the maximum in dielectric side-chains relaxation toward lower temperatures, and of the maximum of $T_{\mathrm{g}}$ toward higher temperatures.

The effect of polymer-filler interaction can be investigated by dielectric measurements, which enables one to study and analyse the mobility of functional groups and segment chains separately. Also, dielectric measurements can detect the effects of different conditions on the different regions of the dielectric dispersion and on the different structural elements of the chains. Therefore, the purpose of this study was to investigate the dielectric loss in a dental polymer, urethane dimethacrylate. Special attention is given to the characterization of the effect of the polymer-filler interaction by determining how a non-compatible inorganic phase modifies the molecular behaviour of the polymer chains and how modification of this phase by silanation can affect these molecular behaviours. The dielectric dispersions and loss tangents of different filler concentrations were measured over a wide range of frequencies and temperatures for zirconia-silica-filled urethane dimethacrylate composites. In addition, the effect of different silanes and different silane concentrations used in treating the zirconia-silica was also measured under the same conditions.

\section{Materials and methods}

\section{Composite system}

Urethane dimethacrylate (UDMA)* was used as a monomer system. Zirconia-silica $(\mathrm{ZS})^{\dagger}$, with a surface area of $1.6 \mathrm{~m}^{2} / \mathrm{g}$ and an average diameter of $1.5 \mu \mathrm{m}$, was used as a filler. 3-Methacryloxypropyltrimethoxysilane (MAPM) and 4-aminobutyltriethoxysilane $(\mathrm{ABTE})^{\ddagger}$ were used as coupling agents to silanate the filler. MAPM was used because it has been shown by Mohsen $\&$ Craig (1995) to be one of the most effective silanating agents for increasing the dispersion and wetting behaviour of the filler particles by the monomer in this particular system, and it also has a carbon double bond to react with the monomer. ABTE was shown to be not effective in wetting the filler particles by the monomer.

\section{Sample preparation}

The filler was silanated by depositing the silanes from an aqueous solution of $75 \%$ ethanol (190\% proof) to $25 \%$ silane (weight ratio) as described by Mohsen $\delta$ Craig (1995). The amount of silane coupling agent $(X)$

* Esschem Company, Essington, PA, U.S.A.

† 3 M Dental Products, St. Paul, MN, U.S.A.

‡ Huls America, Piscataway, NJ, U.S.A.; formerly Petrarch Systems, Bristol, PA, U.S.A. 
used for the filler treatment was based on the following relationship reported by Arkles (1987):

$X=\frac{A}{w} f$

where $X$ is the amount of coupling agent in g needed to obtain a minimum uniform coverage, $f$ is the amount of filler (g), $A$ is the surface area of the filler $\left(\mathrm{m}^{2} / \mathrm{g}\right), w$ is the wetting surface of silane $\left(\mathrm{m}^{2} / \mathrm{g}\right)$. The values for $w$ are listed for each silane in the Petrarch Systems catalogue.

Composites were formulated from UDMA, zirconiasilica and MAPM- or ABTE-silanated zirconia-silica, using DL-camphoroquinone as a catalyst and 2dimethylaminoethylmethacrylate as an accelerator in concentrations described by Douglas, Craig $\&$ Chen (1979). The mixed composite paste was cast into thin films, which were cut into discs $(63.5 \mathrm{~mm}$ diameter and $0.5 \mathrm{~mm}$ thick) for dielectric measurements and was then formed in a right-angle parallelepiped $(54.5 \mathrm{~mm}$ long, $4.8 \mathrm{~mm}$ wide and $2.9 \mathrm{~mm}$ depth) for mechanical measurements. The specimens were cured by visible light at $550 \mathrm{~nm}$ in a TRIAD II oven ${ }^{\S}$ for $5 \mathrm{~min}$ at room temperature, and were then dried for $18 \mathrm{~h}$ in a vacuum at $90-100{ }^{\circ} \mathrm{C}$ to remove moisture and to insure uniform and homogeneous curing. The weight percentages of the unsilanated zirconia-silica in the composite samples were $0,15,45,60$ and 75 wt. $\%$, while the concentration was $75 \mathrm{wt} \%$ MAPM- or ABTE-silanated zirconia-silica in the composite samples. The amount of silane used to treat the filler given by Equation (1) was the minimum uniform coverage $(1 \times)$, and three $(3 \times)$, six $(6 \times)$, ten $(10 \times)$ and 30 times that amount $(30 \times)$.

\section{Dielectric measurements}

The sample was sandwiched between two flat edge-free capacitance plates in the assembled dielectric cell. The upper capacitance plate was pressed against the sample and bolted to the bottom plate. A micrometer was used to raise the bottom plate until the sample touched the upper plate and closed the air gap. The thickness of the sample was recorded from the micrometer. The dielectric cell was covered with a glass container and was flushed with dry nitrogen for $1 \mathrm{~h}$ before the measurements were taken to ensure the absence of moisture. Then, the sample was kept in the dry nitrogen environ-

\footnotetext{
§ Dentsply International, York, PA, U.S.A.
}

ment throughout the experiment. The cell's temperature was lowered by means of liquid nitrogen.

The dielectric loss tangent $\left(\operatorname{Tan}(\delta)_{\varepsilon}\right)$ and capacitance $(C)$ measurements were performed over the frequency range $0.013-200 \mathrm{kHz}$ and a temperature range from -180 to $180^{\circ} \mathrm{C}$ by means of a GenRad 1693 RLC Digibridge ${ }^{\text {II, }}$ which was connected to the dielectric cell and interfaced with a Macintosh PC for data collection. $\operatorname{Tan}(\delta)_{\varepsilon_{0}}$ and capacitance $\left(C_{0}\right)$ were also measured for an empty cell with the same experimental conditions and sample thickness over the frequency range at ambient temperature. The $C_{0}$ measurements were used for the calculation of the dielectric constant $\varepsilon^{\prime}$ and the loss factor $\varepsilon^{\prime \prime}$. The dielectric spectra of five replicas for each filler-monomer ratio were measured, and of three replicas for each silane used, as well as for each amount of silane used to treat the filler.

\section{Mechanical measurements}

The dynamic mechanical measurement was performed by means of a torsion pendulum apparatus Micromecanalyseur system**. In this particular apparatus, the lower part of the sample was clamped rigidly, whereas the upper part was connected to a vertical rod supported by a counter balance. This rod carried another horizontal rod, known as the inertia rod, with weights at the end of it. The inertia rod was displaced slightly to twist and oscillate the sample. The decay of the oscillations was then detected by a galvanometer lamp and scale. The assembly was immersed in liquid nitrogen for cooling to lower temperatures and was heated to higher temperatures gradually. The temperature of the sample was monitored by a thermocouple kept in contact with the sample. The shear modulus $\left(G^{\prime}\right)$ and the mechanical loss tangent $\left(\operatorname{Tan}(\delta)_{G}\right)$ for the unfilled-UDMA was measured over the temperature range $-120-180^{\circ} \mathrm{C}$ and at frequencies of $0 \cdot 01,0 \cdot 1$ and $1 \cdot 0 \mathrm{~Hz}$.

\section{Results}

\section{Assignments of dielectric relaxations of UDMA}

The shear modulus $G^{\prime}$ and the mechanical loss tangent $\left(\operatorname{Tan}(\delta)_{G}\right)$ for the unfilled-UDMA measured at 0.01 , $0 \cdot 1$ and $1.0 \mathrm{~Hz}$ are plotted against temperature in Fig. 1

\footnotetext{
"I GenRad, Incorporated, Concord, MA, U.S.A.

** INSA-METRAVIB, Lyon, France.
} 
The $G^{\prime}$ and the $\operatorname{Tan}(\delta)_{G}$ curves show three mechanical relaxations appearing as $\alpha-, \beta$ - and $\gamma$-peaks.

The dielectric loss tangent $\operatorname{Tan}(\delta)_{\varepsilon}$ values exhibited by the vacuum-dried unfilled-UDMA measured at different frequencies are plotted against temperature in Fig. 2. The $\operatorname{Tan}(\delta)_{\varepsilon}$ curves show two dielectric relaxation peaks appearing as $\beta$ - and $\alpha$-peaks, followed by a rapidly increasing loss tangent with increasing temperature.

The isothermal spectra of the dielectric permittivity $\varepsilon^{\prime}$ and the loss $\varepsilon^{\prime \prime}$ curves at low temperatures were calculated for vacuum-dried unfilled-UDMA using the relationships given by McCrum, Read \& William (1967) and their values are plotted against $\log f$ in Fig. 3. The $\varepsilon^{\prime \prime}$ curves show typical sub- $T_{\mathrm{g}}$ (very broad), $\beta$-relaxations, where the values of $\varepsilon^{\prime \prime}$ increased with temperature in the range -60 to $10^{\circ} \mathrm{C}$ and with increasing frequency. However, the isothermal spectra of the $\varepsilon^{\prime}$ and $\varepsilon^{\prime \prime}$ curves at high temperatures and low frequencies calculated for the dried unfilled-UDMA against $\log f$ showed a large contribution from the DC conductivity near the $T_{\mathrm{g}}$, which masked the $\varepsilon^{\prime \prime}$ peak due to the segmental motion of the main chains. Therefore, the dipolar and ionic natures of the relaxation processes observed were resolved using a relationship given by Moynihan, Boesch \& Laberge (1973) by converting the conductance and the capacitance into the complex electrical modulus formalism,

$M^{*}=\left(\varepsilon^{*}\right)^{-1}=M^{\prime}+\mathrm{i} M^{\prime \prime}$

then, the real component $M^{\prime}$ and the imaginary component $M^{\prime \prime}$ of the complex electrical modulus were calculated at several temperatures and their values were plotted against the high frequencies in Fig. 4. Such calculations allow one to observe the $\alpha$-relaxation peaks more clearly. Further, with close examination of the low-frequency region, it is observed that the $M^{\prime \prime}$ curves present an onset of a new peak $\left(\alpha^{\prime}\right)$ in Fig. 5, which is attributed to a space charge and/or a Maxwell-Wagner-Sillars polarization.

The peaks of the angular frequency $(\ln \omega)$, at which the loss tangent $\operatorname{Tan}(\delta)_{\varepsilon}$ or $\operatorname{Tan}(\delta)_{G}$ was a maximum for the unfilled-UDMA, are plotted against the reciprocal temperature in Fig. 6. The activation energies were
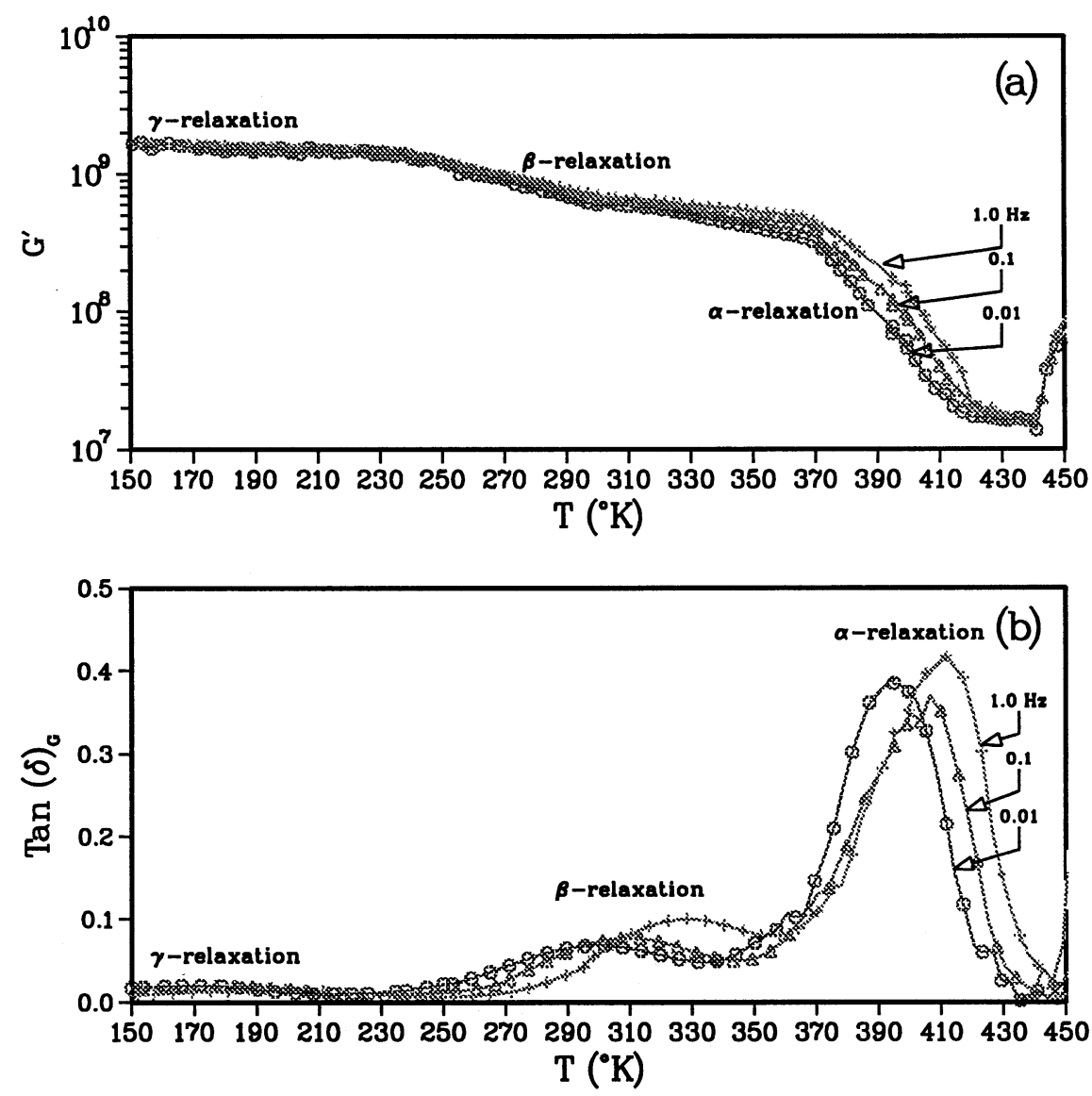

Fig. 1. (a) $G^{\prime}$ and (b) $\operatorname{Tan}(\delta)_{G}$ against temperature for unfilled-UDMA at $0 \cdot 01,0 \cdot 1$ and $1 \cdot 0 \mathrm{~Hz}$. 
Fig. 2. $\operatorname{Tan}(\delta)_{\varepsilon}$ vs. temperature for unfilled-UDMA at $0 \cdot 053,0 \cdot 125,0 \cdot 252$, $1 \cdot 0,10 \cdot 0$ and $100 \cdot 0 \mathrm{kHz}$.

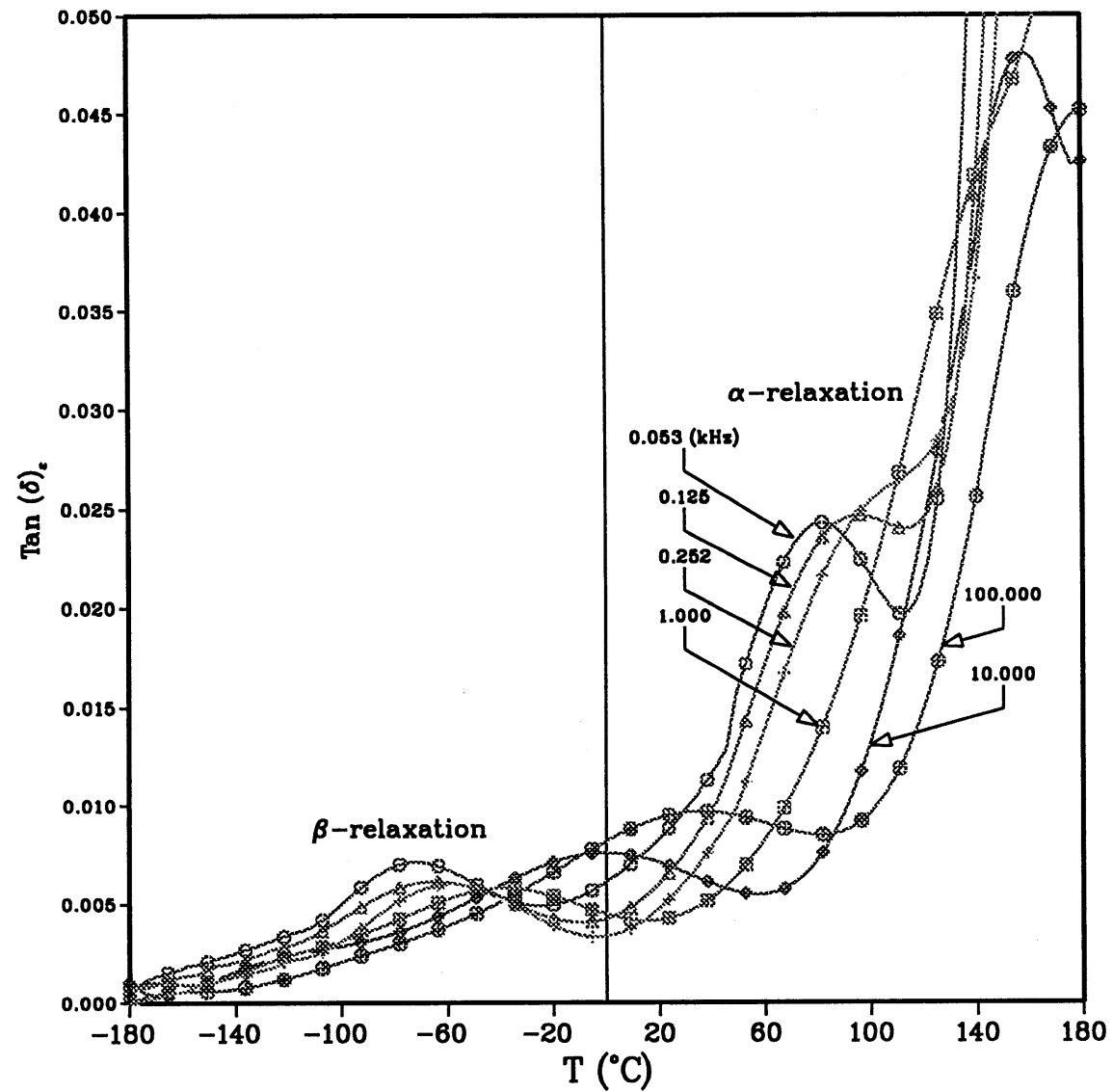

calculated from the slopes using the Arrhenius relationship given by McCrum et al. (1967), and the values are presented in Table 1.

The effect of filler incorporation on the dielectric relaxations of UDMA

The dielectric loss tangent $\left(\operatorname{Tan}(\delta)_{\varepsilon}\right)$ values exhibited by vacuum-dried UDMA filled with $0-75 \mathrm{wt}$.\% zirconia-silica at $10 \mathrm{kHz}$ are plotted against temperature in Fig. 7. The peak's maximum temperature obtained from the measured $\operatorname{Tan}(\delta)_{\varepsilon}$ curves (five replicates) were averaged and their values are presented in Table 2. Several observations can be noted as a result of filler incorporation. First, the intensities of $\operatorname{Tan}(\delta)_{\varepsilon}$ of the $\alpha$ and $\beta$-relaxations decreased with increasing amounts of zirconia-silica. Second, the $\alpha$-relaxations were shifted to higher temperatures while the $\beta$-relaxations were shifted to lower temperatures. The $\beta$-relaxations also became broader with the increase of filler. In addition, the $\alpha$-relaxation was totally obstructed with higher filler incorporation, especially at low frequencies and high temperatures, as a result of the increase in the DC conductivity and the shift of the $\alpha$-relaxation to higher temperatures.

The thickness of the surface layer $(\Delta r)$ was calculated using the relationship given by Ziegel $\&$ Romanov (1973),

$\operatorname{Tan} \delta_{\mathrm{C}}=\frac{\operatorname{Tan} \delta_{\mathrm{O}}}{\left(1+1 \cdot 5 \phi_{\mathrm{F}} B\right)}$

where $\operatorname{Tan} \delta_{\mathrm{C}}$ and $\operatorname{Tan} \delta_{\mathrm{O}}$ are the loss tangent of the composite and the polymer, respectively, $\phi_{\mathrm{F}}$ is the volume fraction filler, and

$B=\left(1+\frac{\Delta R}{R_{\mathrm{O}}}\right)^{3}$

where $R_{\mathrm{O}}$ is the filler radius. The values of $\Delta r$ are shown in Table 3.

The activation energies $(\Delta H)$ and the pre-exponential factors $\left(\tau_{0}\right)$ were determined from the slopes and 
intercepts of the curves of $\ln \omega$ against the reciprocal temperature using the Arrhenius relation

$\tau=\tau_{0} \exp \left(\frac{-\Delta H}{R T}\right)$

where $\tau$ is the relaxation time $(\mathrm{Hz}), \tau_{0}$ is the pre-exponential factor $(\mathrm{Hz}), \Delta H$ is the activation energy (kcal/ $\mathrm{mol}), R$ is the universal gas constant $(\mathrm{kcal} / \mathrm{mol} \mathrm{K})$, and $T$ is the temperature $(\mathrm{K})$.

The activation entropies $(\Delta S)$ were calculated using the definition of the pre-exponential factors determined from the Arrhenius relationship given by McCrum et al. (1967), namely

$\tau_{0}=\frac{1}{v} \exp \left(\frac{-\Delta S}{R}\right)$

where

$\frac{1}{v}=\frac{h}{k T}$

The values for $\Delta H, \Delta S$ and $\tau_{0}$ are presented in Table 4.
The effect of silanation of filler on the dielectric relaxations of UDMA

The temperatures of the $\alpha$ - and $\beta$-relaxations for vacuum-dried UDMA filled with 75 wt.\% MAPMsilanated zirconia-silica obtained from the measured $\operatorname{Tan}(\delta)_{\varepsilon}$ at different frequencies are shown in Table 5. From these results one can observe a definite trend as a result of increasing MAPM treatment. The $\alpha$-relaxations were shifted to higher temperatures at $1 \times$, then shifted to lower temperatures at higher concentrations of MAPM. In addition, the $\beta$-relaxations were shifted to higher temperatures when the filler was treated with low amounts of silane, and then were shifted back to lower temperatures with high amounts of silane. A comparison of $M^{\prime}$ and $M^{\prime \prime}$ isothermal curves at $180^{\circ} \mathrm{C}$ over the low frequency range is shown in Fig. 8 for the unfilled-, 75 wt. \% filled- and 75 wt. \% silanated filledUDMA, with different amounts of MAPM silane. Figure 8 shows that the presence of the silane between the filler and the polymer reduces the effect of space
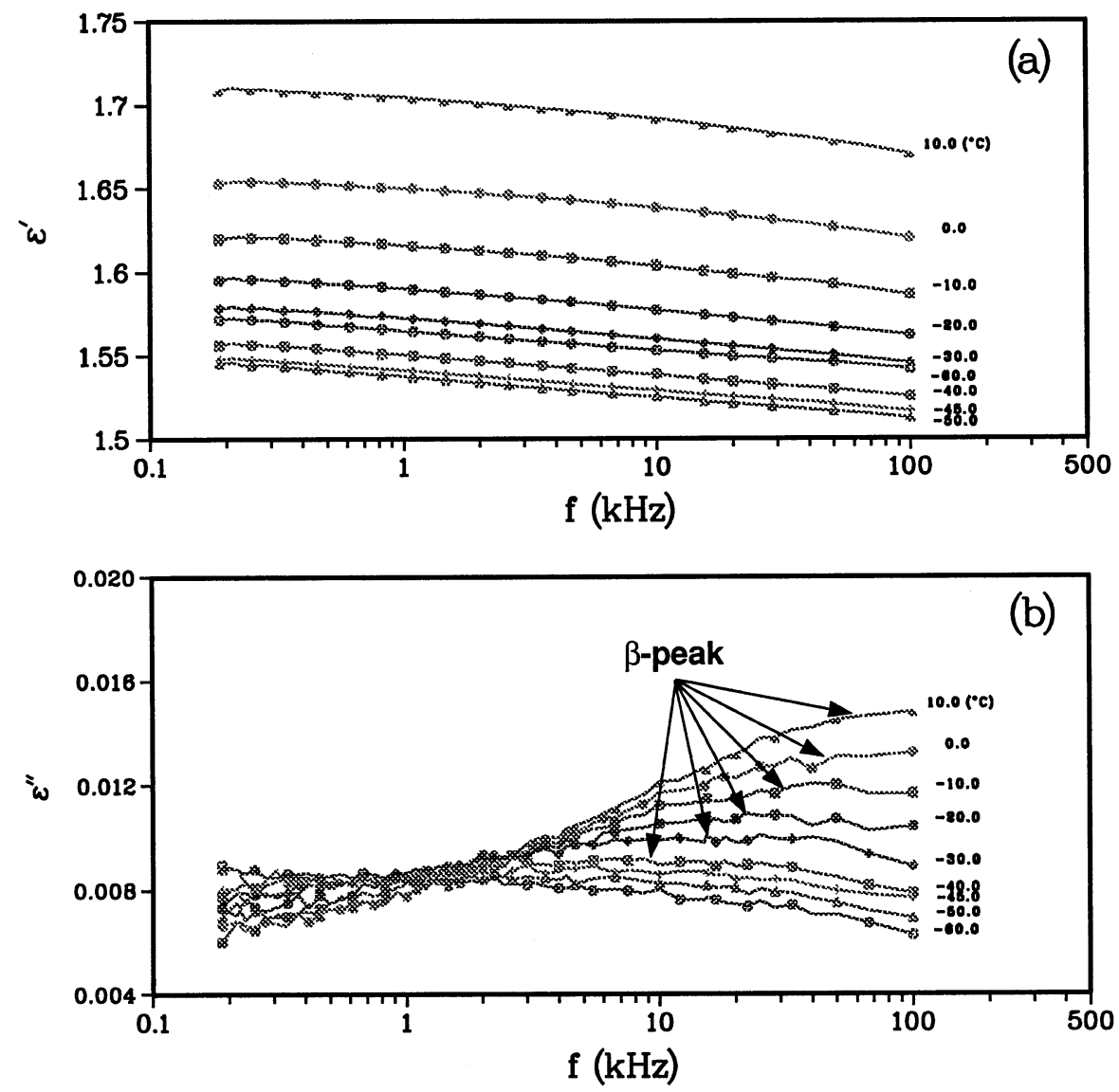

Fig. 3. The spectra of (a) $\varepsilon^{\prime}$ and (b) $\varepsilon^{\prime \prime}$ vs. frequency for $\beta$-relaxation of unfilled-UDMA over the temperature range -60 to $10^{\circ} \mathrm{C}$. 
Fig. 4. The spectra of (a) $M^{\prime}$ and (b) $M^{\prime \prime}$ against frequency for $\alpha$-relaxation of unfilled-UDMA over the temperature range $100-175^{\circ} \mathrm{C}$.
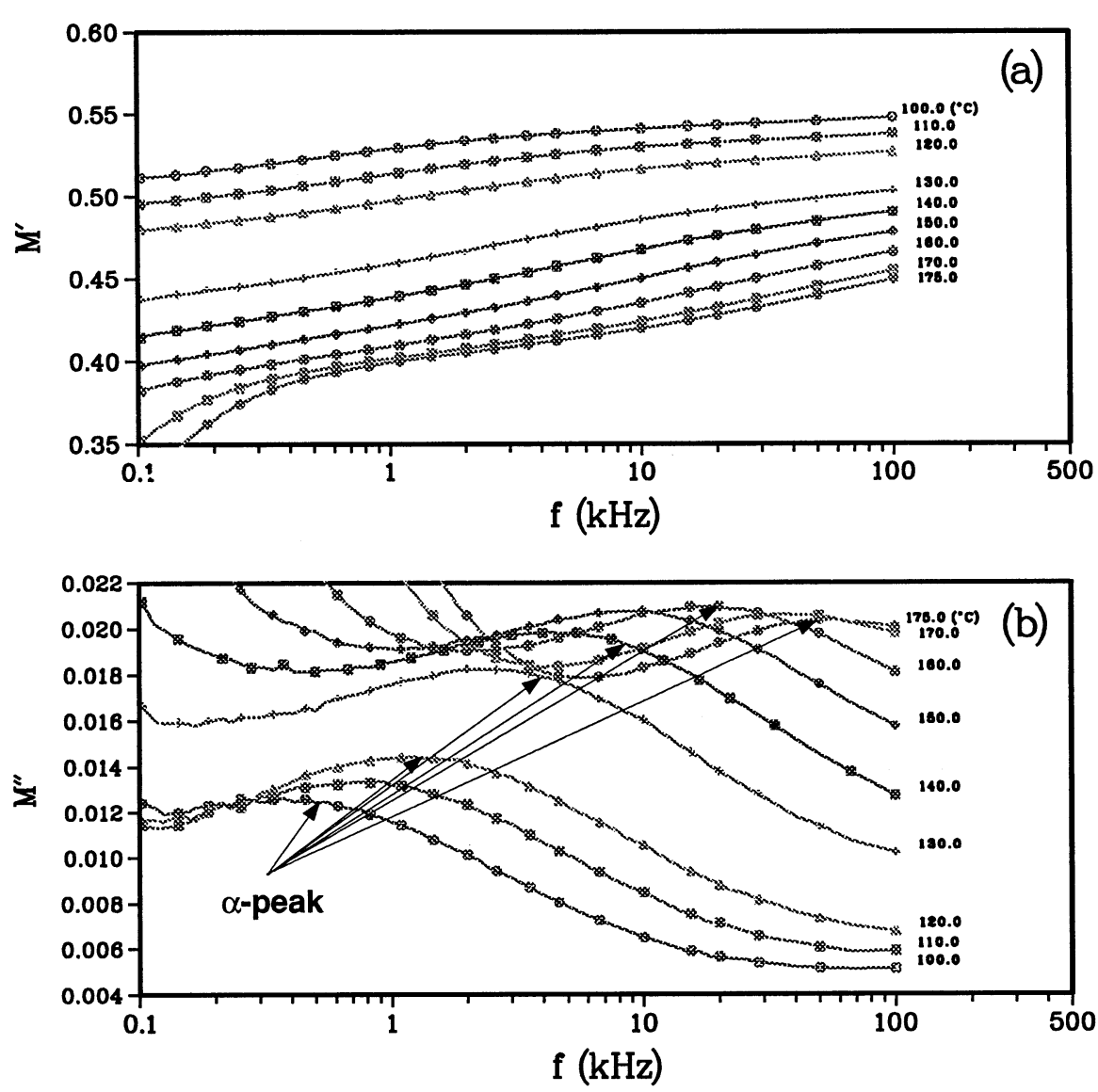

charge separation that accumulates due to incompatibility of the interface. However, the silane presence did not prevent the rapid increase of the $\operatorname{Tan}(\delta)_{\varepsilon}$ and $M^{\prime \prime}$ values at low frequencies and high temperatures. This observation further supports the presence of the DC conduction mechanism resulting from the motion of hydrogen protons that act as current carriers.

The temperatures of the peak's maxima for the $\alpha$ and $\beta$-relaxations for vacuum-dried UDMA filled with 75 wt. \% ABTE-silanated zirconia-silica obtained from the measured $\operatorname{Tan}(\delta)_{\varepsilon}$ at different frequencies are shown in Table 6. In general, these results show shifts of the $\alpha$-and $\beta$-relaxations to lower temperatures with the increase in filler silanation with ABTE. Further, an extra peak emerged in the high-temperature region when the filler was silanated with 30 times the minimum uniform coverage $(30 \times)$. This new peak was superimposed on the $\alpha$-relaxation peak, which appeared as a shoulder at around $70{ }^{\circ} \mathrm{C}$ at $100 \mathrm{kHz}$.

The ionic and dipolar nature of the relaxation were resolved by calculating $M^{\prime}$ and $M^{\prime \prime}$ over the tempera- ture range $120-180^{\circ} \mathrm{C}$, and the values are plotted against the low-frequency range in Fig. 9 for the $3 \times$ ABTE-silanated zirconia-silica-filled UDMA, while they are plotted against the entire frequency range in Fig. 10 for the $30 \times$ ABTE-silanated zirconia-silicafilled UDMA. These results show increasing values of $M^{\prime \prime}$ at the low-frequency region that blocked the onset of the $\alpha$-relaxation. These rising values were due to an onset of a new peak that started to develop at high temperatures and low frequencies when the filler was silanated with $3 \times$ ABTE (Fig. 9). This new peak is further enhanced and shown more clearly in Fig. 10b, which was attributed to space charge separation at the interface.

The activation energies $(\Delta H)$, the half-width of the bands $\left(\Delta_{1 / 2}\right)$ given by McCrum et al. (1967), the intensities of $\operatorname{Tan}(\delta)_{\varepsilon}(\lambda)$, and the dielectric increments $(\Delta \varepsilon)$ were determined for MAPM- and ABTE-treated filler as a function of the increase in the silane concentration, and the values are shown in Tables 7 and 8, respectively. 


\section{Discussion}

Assignments of dielectric relaxations for UDMA

Since the UDMA monomer structural formula sketched in Fig. 11 consists of urethane linkage (-NHCOO-), separated by $\left(-\left(\mathrm{CH}_{2}\right)_{8}^{-}\right)$and containing a methacrylate group at both ends to react by free radical polymerization to form the polymer, the main chain structure for the UDMA polymer closely resembles those of polyurethane and polyamide, shown in Figs $1 \mathrm{la}$ and b, respectively.

In polyurethanes and polyamides, the most pronounced dispersion corresponds to the glass-rubber transition $\left(T_{\mathrm{g}}\right)$ of the amorphous phase, the secondary relaxation $(\beta)$ corresponds to rotation of unbound amide groups or to the motion of a water-polymer complex, and the third relaxation $(\gamma)$ corresponds to local mode motions of the main chain given by McCrum et al. (1967) and Hedvig (1977). Mechanical and dielectric losses in nylon 6, nylon 66 and urethane- acrylate oligomer have been measured by Woodward, Sauer, Deeley \& Kline (1957), McCrum et al. (1967), Wadhwa $\&$ Walsh (1982) and Boyd (1959). The $\alpha$-relaxation has been attributed primarily to the segmental chain motion in the amorphous regions by Woodward et al. (1957), Boyd (1959), McCrum et al. (1967) and Wadhwa \& Walsh (1982). The $\beta$-relaxation has been assigned by Woodward et al. (1957) and Boyd (1959) to the motion of unbound amides, while the $\gamma$-relaxation has been assigned by Woodward et al. (1957) and McCrum et al. (1967) to the motion of $\left(\mathrm{CH}_{2}\right)_{n}$ sequences. Therefore, the main peak ( $\alpha$-peak) in UDMA can be assigned to the $T_{\mathrm{g}}$, the $\beta$-peak to the motion of unbound amides, since the relaxation did not disappear with vacuum drying, and the $\gamma$-peak can be assigned to the motions of $\left(\mathrm{CH}_{2}\right)_{n}$ sequences.

The shape of the relaxation transitions of $\operatorname{Tan}(\delta)_{G}$ and the appearance of the relaxation peaks for the UDMA coincided with thermomechanical relaxations and transitions for the polyurethanes and polyamides. However, the maximum for UDMA's peaks occurred at
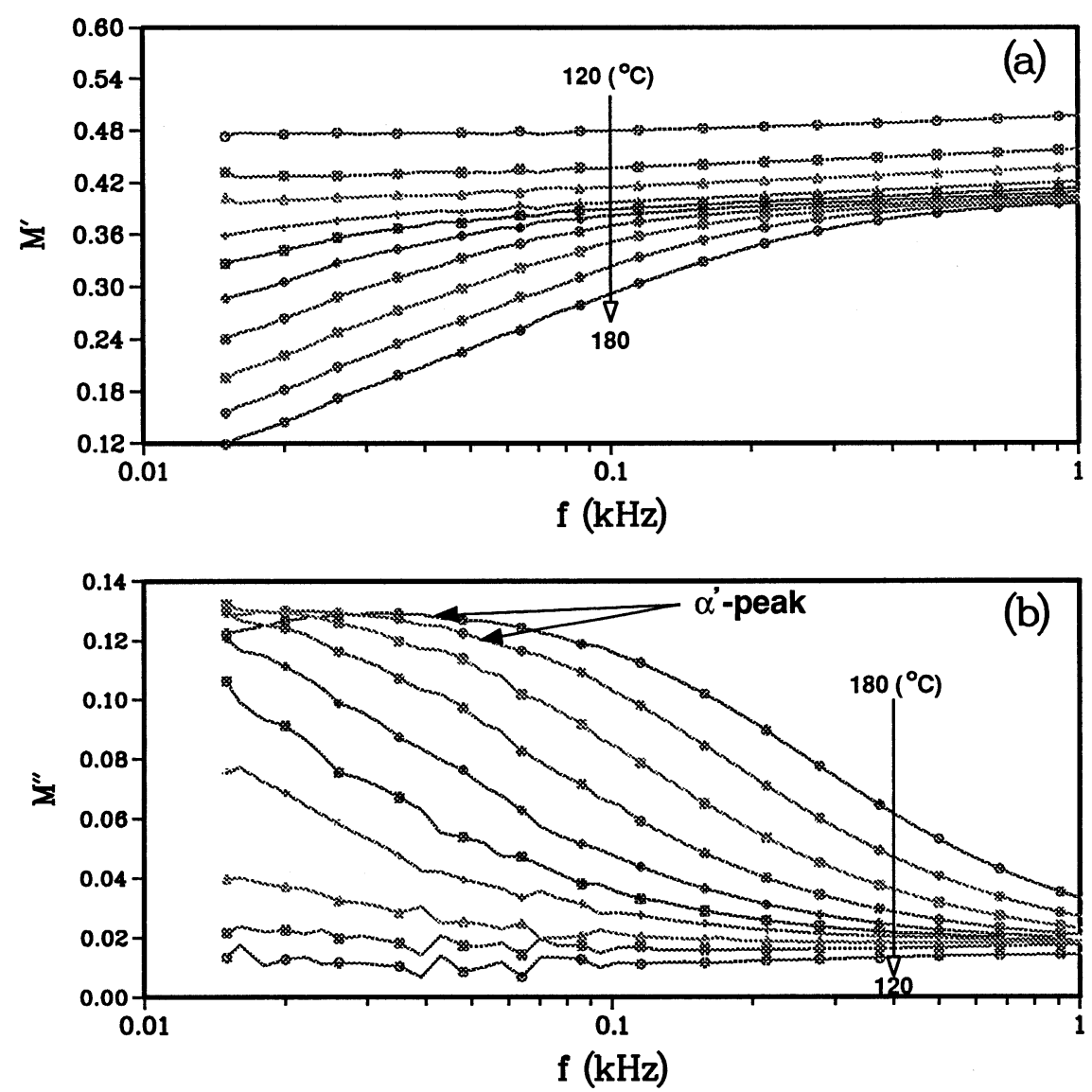

Fig. 5. The spectra of (a) $M^{\prime}$ and (b) $M^{\prime \prime}$ against frequency for $\alpha^{\prime}$-relaxation of unfilled-UDMA over the frequency range $0.01-1 \cdot 0 \mathrm{kHz}$ and over the temperature range $120-180^{\circ} \mathrm{C}$. 


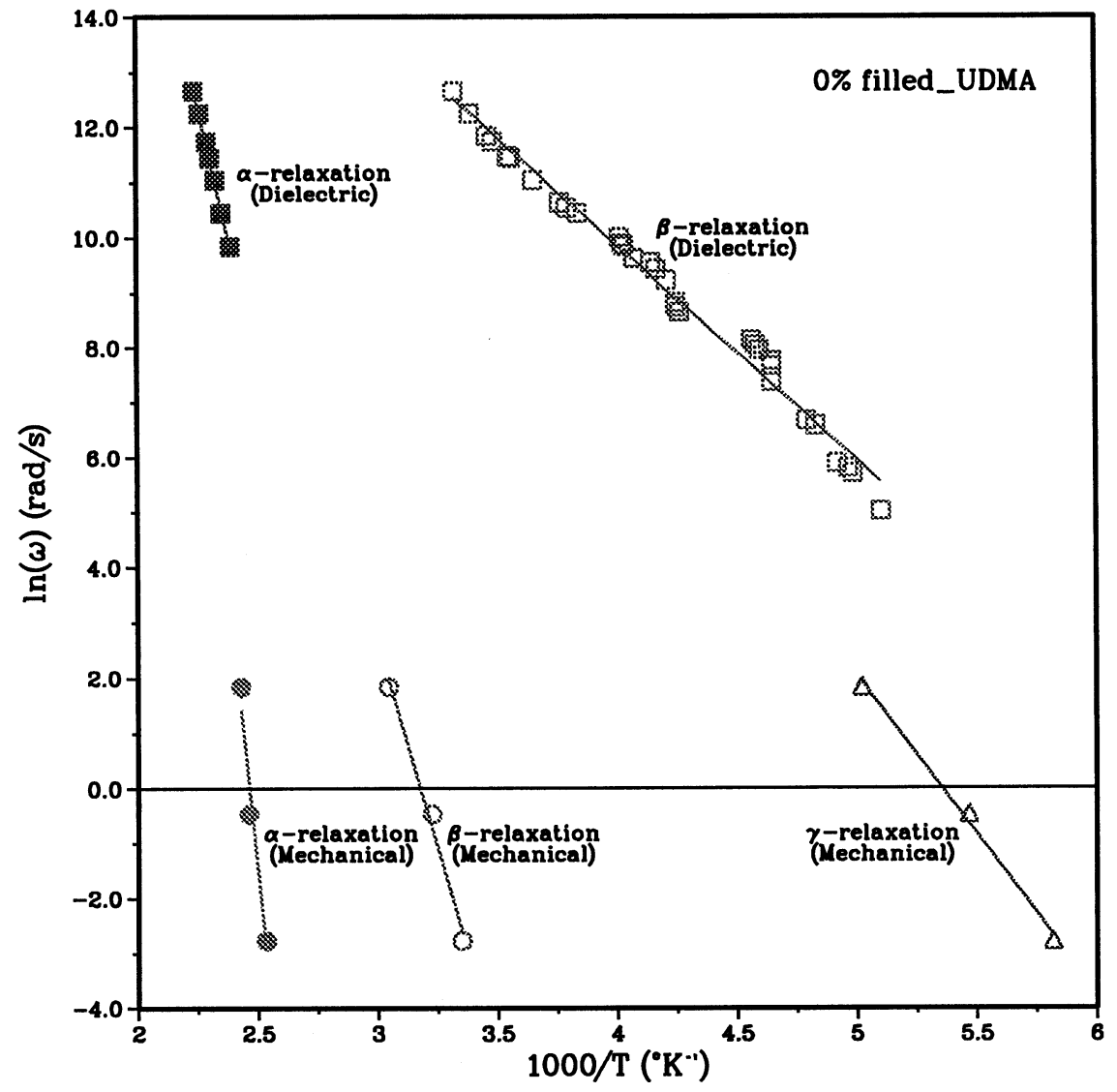

Fig. 6. The angular frequency of $\operatorname{Tan}(\delta)_{\varepsilon}$ and $\operatorname{Tan}(\delta)_{G}$ maximum for $\alpha-$, $\beta$ - and $\gamma$-relaxations against $1 / T\left(\mathrm{~K}^{-1}\right)$ obtained by dielectric and mechanical measurements for unfilled-UDMA. much higher temperatures. This shift to higher temperatures has been seen by McCrum et al. (1967) when the $\left(\mathrm{CH}_{2}\right)_{n}$ sequences decreased in length, a result found for polyamides and polyurethanes, where nylon 66 has a higher $T_{\mathrm{g}}$ than nylon 11 . This effect is also true in the case of UDMA, where $n=5$ in the $\left(\mathrm{CH}_{2}\right)_{n}$ sequences between the urethane linkages and $n=2$ between the urethane and the methacrylate groups. Further, the presence of methyl groups attached to the methacrylate groups and to the $\left(\mathrm{CH}_{2}\right)_{n}$ sequences affects the mode of packing of the molecules so as to increase the density. In the absence of these bulky groups, the strict requirements of hydrogen bonds prevent the molecules from packing as closely as they would if van der Waals forces were dominant. The presence of the bulky methyl groups lowers the number of inter-chain hydrogen bonds, enabling the chains to pack more closely, and this could be responsible for the shift of the peaks to higher temperatures.

With the exception of the disappearance of the $\gamma$ peak and of the elevation of $\operatorname{Tan}(\delta)_{\varepsilon}$ at high tempera- tures and low frequencies, the two observed dielectric relaxation peaks for UDMA coincided with the thermomechanical relaxations in Fig. 1. By comparing the location of these peaks with those by Woodward et al. (1957), Boyd (1959), McCrum et al. (1967) and Wadhwa $\delta$ Walsh (1982), one can give the $\alpha$ - and $\beta$-relaxations the same assignments as those observed in the mechanical measurements and those in the dielectric measurements. However, the values of the dielectric loss for UDMA are much higher than the values of the mechanical losses, probably due to the decrease of the $\left(\mathrm{CH}_{2}\right)_{n}$ sequences' length in the main chain and the

Table 1. Activation energies from dielectric and mechanical measurements for unfilled-UDMA polymer

\begin{tabular}{lll}
\hline & $\begin{array}{l}\text { UDMA dielectric } \\
\text { Activation energy } \\
(\mathrm{kcal} / \mathrm{mol})\end{array}$ & $\begin{array}{l}\text { UDMA mechanical } \\
\text { Activation energy } \\
(\mathrm{kcal} / \mathrm{mol})\end{array}$ \\
\hline$\alpha$ & $40 \cdot 4 \pm 6 \cdot 4$ & $89 \cdot 1$ \\
$\beta$ & $7 \cdot 5 \pm 0 \cdot 5$ & $30 \cdot 1$ \\
$\gamma$ & - & $11 \cdot 5$ \\
\hline
\end{tabular}


Fig. 7. $\operatorname{Tan}(\delta)_{\varepsilon}$ vs. temperature at $10.0 \mathrm{kHz}$ for $0,15,45,60$ and 75 wt.\% zirconia-silica-filled UDMA.

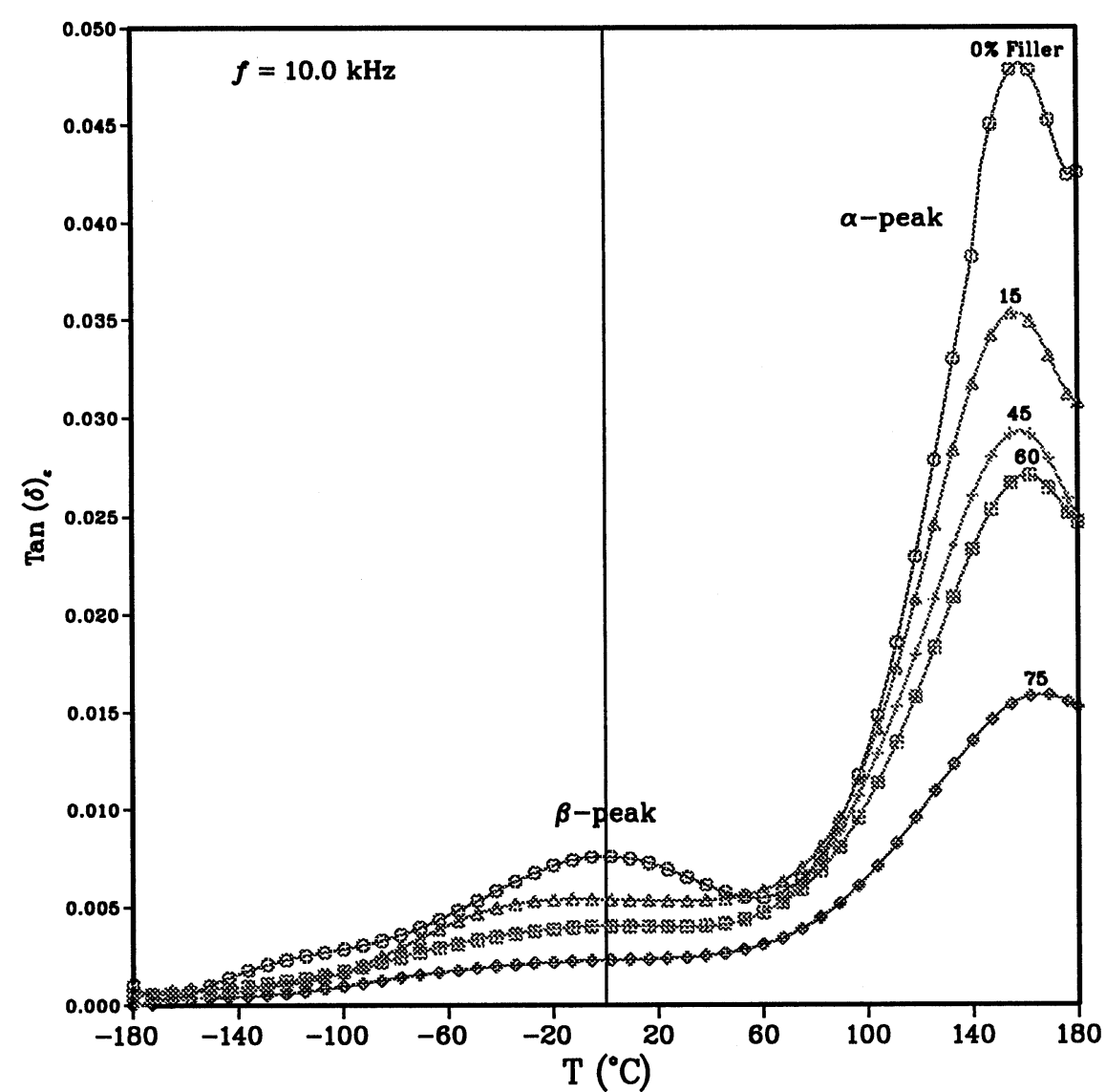

increase of the density of packing of the molecule, as discussed previously.

The activation energy values of the mechanical experiments are much higher than those of the dielectric measurements. This can be explained by the fact that the loss values were measured at much lower frequencies in the mechanical than the dielectric experiment. At such low frequencies, the slope of $\ln \omega$ against the reciprocal temperature is sharper, especially for the high-temperature relaxations. Thus, one would expect higher activation energies. Further, in the dielectric experiments, the loss is in measuring the net effective dipole moment in the interaction with the alternating electric field as opposed to the actual dynamic motion of the chains, which is measured in the mechanical experiment.

Comparing the activation energies calculated from the dielectric measurements with those reported in the literature, the apparent activation energy from the $\alpha$ relaxation peak reported by Boyd (1959) was $46 \mathrm{kcal} /$ mol for nylon 66, while those reported by Baker $\delta$ Yager (1942) were 24 and $42 \mathrm{kcal} / \mathrm{mol}$ for nylon 610 at low and high temperatures, respectively. These values compare well with the value of $40 \mathrm{kcal} / \mathrm{mol}$ (Table 1)

Table 2. Average maximum peaks temperatures $\left({ }^{\circ} \mathrm{C}\right)$ from $\operatorname{Tan}(\delta)_{\varepsilon}$ measurements for different amounts of zirconia-silica dispersed in UDMA for $\alpha$-relaxations at 10.0 and $33.3 \mathrm{kHz}$ and for $\beta$-relaxations at 0.252 and $1.0 \mathrm{kHz}$

\begin{tabular}{|c|c|c|c|c|}
\hline \multirow{3}{*}{$\begin{array}{l}\% \\
\text { Filler }\end{array}$} & \multicolumn{4}{|c|}{ Average maximum peak temperature $\left({ }^{\circ} \mathrm{C}\right)$} \\
\hline & \multicolumn{2}{|c|}{$\alpha$-Relaxation } & \multicolumn{2}{|l|}{$\beta$-Relaxation } \\
\hline & $10 \cdot 0(\mathrm{kHz})$ & $33 \cdot 3(\mathrm{kHz})$ & $0 \cdot 252(\mathrm{kHz})$ & $1 \cdot 0(\mathrm{kHz})$ \\
\hline 0 & $156 \cdot 6 \pm 1 \cdot 6$ & $168.9 \pm 0.5$ & $-59 \cdot 8 \pm 1 \cdot 7$ & $-38.8 \pm 2 \cdot 0$ \\
\hline 15 & $155 \cdot 6 \pm 1 \cdot 1$ & $170 \cdot 5 \pm 0.5$ & $-62 \cdot 6 \pm 5 \cdot 1$ & $-43 \cdot 2 \pm 0 \cdot 6$ \\
\hline 45 & $158 \cdot 8 \pm 1 \cdot 2$ & $171 \cdot 7 \pm 0.6$ & $-60 \cdot 0 \pm 1 \cdot 2$ & $-44 \cdot 2 \pm 2 \cdot 9$ \\
\hline 60 & $161 \cdot 4 \pm 0 \cdot 4$ & $172 \cdot 4 \pm 0.5$ & $-60 \cdot 0 \pm 3 \cdot 2$ & $-45 \cdot 0 \pm 0 \cdot 0$ \\
\hline 75 & $166 \cdot 4 \pm 0 \cdot 5$ & $175 \cdot 0 \pm 0 \cdot 1$ & $-69 \cdot 1 \pm 4 \cdot 2$ & $-43 \cdot 3 \pm 0.9$ \\
\hline
\end{tabular}


Table 3. Thickness of the adsorbed UDMA layer onto the filler as a function of concentration of the dispersed phase

\begin{tabular}{rlllll}
\hline$\%$ Filler & Temperature $\left({ }^{\circ} \mathrm{C}\right)$ & Tan $\delta_{\mathrm{C}}$ at $20.0 \mathrm{kHz}$ & $\phi_{\mathrm{F}}$ & $\phi_{\varepsilon}$ & $\Delta r(\mu \mathrm{m})$ \\
\hline 0 & 170.9 & 0.04774 & - & - & - \\
15 & $162 \cdot 2$ & 0.03369 & 0.066 & 0.278 & 0.459 \\
45 & $165 \cdot 6$ & 0.02245 & 0.248 & 0.751 & 0.335 \\
60 & 166.9 & 0.02185 & 0.376 & 0.931 & 0.264 \\
75 & 171.9 & 0.01793 & 0.547 & $1 \cdot 187$ & 0.221 \\
\hline
\end{tabular}

Table 4. Activation energies $(\Delta H)$, pre-exponential factors $\left(\tau_{0}\right)$ and activation entropies $(\Delta S)$ for $\alpha$ - and $\beta$-dielectric relaxation processes at 432 and $232 \mathrm{~K}$, respectively, as a function of per cent filler dispersion in UDMA

\begin{tabular}{|c|c|c|c|c|c|c|}
\hline \multirow[b]{2}{*}{$\%$ Filler } & \multicolumn{3}{|l|}{$\alpha$-Relaxation } & \multicolumn{3}{|l|}{$\beta$-Relaxation } \\
\hline & $\Delta H(\mathrm{kcal} / \mathrm{mol})$ & $\Delta S(\mathrm{kcal} / \mathrm{mol} \mathrm{K})$ & $\tau_{\mathrm{o}}\left(\mathrm{Hz} \times 10^{-26}\right)$ & $\Delta H(\mathrm{kcal} / \mathrm{mol})$ & $\Delta S(\mathrm{kcal} / \mathrm{mol} \mathrm{K})$ & $\tau_{0}\left(\mathrm{~Hz} \times 10^{-12}\right)$ \\
\hline 0 & $40 \cdot 4 \pm 6 \cdot 4$ & $0 \cdot 167$ & $57 \cdot 0$ & $7 \cdot 5 \pm 0 \cdot 5$ & $0 \cdot 107$ & $3 \cdot 2$ \\
\hline 15 & $39 \cdot 7 \pm 2.9$ & $0 \cdot 171$ & $8 \cdot 0$ & $7 \cdot 9 \pm 0 \cdot 3$ & $0 \cdot 109$ & $1 \cdot 2$ \\
\hline 45 & $42 \cdot 0 \pm 1 \cdot 6$ & $0 \cdot 176$ & $0 \cdot 45$ & $7 \cdot 5 \pm 0.5$ & $0 \cdot 107$ & $3 \cdot 3$ \\
\hline 60 & $45 \cdot 3 \pm 3 \cdot 3$ & $0 \cdot 181$ & $0 \cdot 049$ & $7 \cdot 2 \pm 0 \cdot 3$ & $0 \cdot 106$ & $4 \cdot 5$ \\
\hline 75 & $49 \cdot 9 \pm 0 \cdot 6$ & $0 \cdot 184$ & 0.011 & $6 \cdot 7 \pm 0 \cdot 2$ & $0 \cdot 105$ & $7 \cdot 3$ \\
\hline
\end{tabular}

Table 5. Average maximum peaks temperatures $\left({ }^{\circ} \mathrm{C}\right)$ from $\operatorname{Tan}(\delta)_{\varepsilon}$ measurements for different amounts of MAPM treatment of 75 wt. \% zirconia-silica dispersed in UDMA for $\alpha$-relaxations at 5.5 and $33.3 \mathrm{kHz}$ and for $\beta$-relaxations at 0.252 and $1.0 \mathrm{kHz}$

\begin{tabular}{|c|c|c|c|c|}
\hline \multirow[b]{3}{*}{ MAPM amount } & \multicolumn{4}{|c|}{ Average maximum peak temperature $\left({ }^{\circ} \mathrm{C}\right)$} \\
\hline & \multicolumn{2}{|c|}{$\alpha$-Relaxation } & \multicolumn{2}{|l|}{$\beta$-Relaxation } \\
\hline & $5 \cdot 5 \mathrm{kHz}$ & $33 \cdot 3 \mathrm{kHz}$ & $0 \cdot 252 \mathrm{kHz}$ & $1 \cdot 0 \mathrm{kHz}$ \\
\hline 0 & $165 \cdot 4 \pm 0 \cdot 5$ & $175 \cdot 0 \pm 0 \cdot 5$ & $-69 \cdot 1 \pm 4 \cdot 2$ & $-43 \cdot 3 \pm 0.9$ \\
\hline $1 \times$ & $163 \cdot 8 \pm 2 \cdot 0$ & $176 \cdot 0 \pm 2 \cdot 0$ & $-49 \cdot 1 \pm 6 \cdot 0$ & $-38.5 \pm 3.5$ \\
\hline $3 \times$ & $160 \cdot 5 \pm 3 \cdot 0$ & $172 \cdot 9 \pm 1 \cdot 5$ & $-39 \cdot 9 \pm 6 \cdot 5$ & $-33 \cdot 0 \pm 5 \cdot 0$ \\
\hline $6 \times$ & $158 \cdot 5 \pm 3 \cdot 0$ & $169.9 \pm 3.5$ & $-43 \cdot 0 \pm 4 \cdot 8$ & $-38.2 \pm 5.9$ \\
\hline $10 \times$ & $155 \cdot 0 \pm 2 \cdot 3$ & $169 \cdot 5 \pm 2 \cdot 8$ & $-54 \cdot 5 \pm 5 \cdot 7$ & $-39 \cdot 7 \pm 2 \cdot 7$ \\
\hline $30 \times$ & $145 \cdot 3 \pm 6 \cdot 1$ & $162 \cdot 2 \pm 5 \cdot 8$ & $-60 \cdot 0 \pm 6 \cdot 2$ & $-50 \cdot 0 \pm 3 \cdot 4$ \\
\hline
\end{tabular}

for the $\alpha$-relaxation of UDMA determined from the dielectric measurements.

In these types of polymers, where the polar groups are contained in the main chain, one would expect the intensity of the dielectric loss of the $\alpha$-peak to be dominant. This is the case for UDMA as illustrated in Fig. 2. In addition, by comparing the location of $\operatorname{Tan}(\delta)_{\varepsilon}$ peaks of UDMA with those reported, one can give the $\alpha$ - and $\beta$-relaxations the same assignments as those observed in the mechanical and the dielectric measurements. So it would be logical to assign the $\alpha$-relaxation to the initiation of the micro-Brownian motion of the molecular chains from the frozen state, and the $\beta$-relaxation to the motion of the free amide groups. It would also be suitable to assign the increase of the $\operatorname{Tan}(\delta)_{\varepsilon}$ to the superposition of the space charge separation and the DC conductivity, which is due to the movements of the protons in the hydrogen bonds of the amide groups.

The effect of filler incorporation on the dielectric relaxations of UDMA

The effect of the filler on the $\alpha$-relaxation. It was observed that the existence of an interface brings about substantial changes in the relaxation behaviour of the glass 
Fig. 8. The spectra of (a) $M^{\prime}$ and (b) $M^{\prime \prime}$ vs. frequency for $\alpha^{\prime}$-relaxation of unfilled-UDMA and $0-30 \times$ MAPM-treated zirconia-silica-filled UDMA at $180^{\circ} \mathrm{C}$ and the frequency range $0.01-1 \cdot 0 \mathrm{kHz}$.
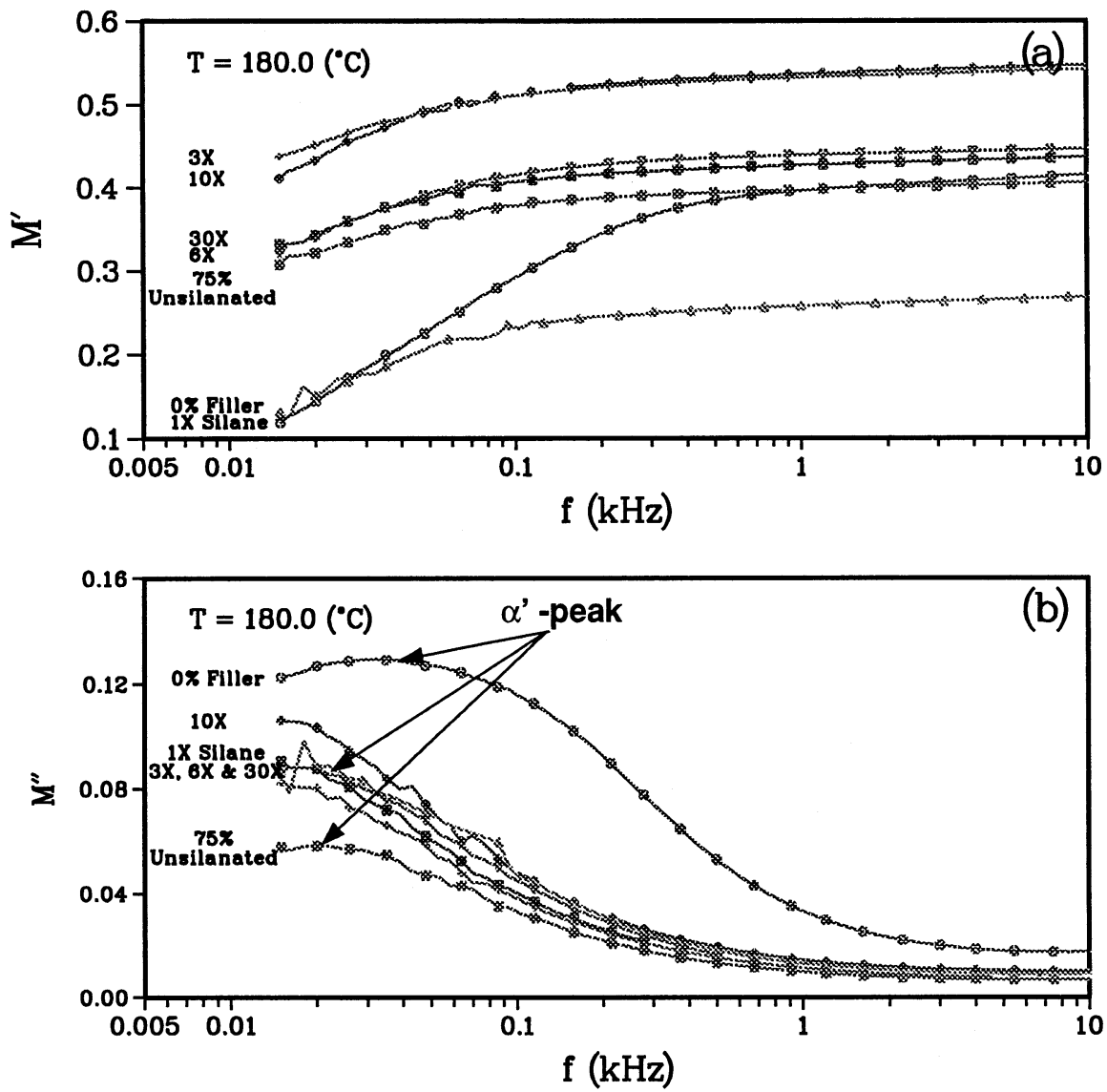

transition. When the matrix was reinforced with zirconia-silica, the filled polymer consisted of particles bearing on their surface polymer layers of various thicknesses. As the filler concentration increased, the thickness of the surface layer decreased as was shown in Table 3. As the thickness of the surface layer decreased, the glass transition was shifted to a higher temperature or a lower frequency if the variable was the temperature or the frequency, respectively. Further, the intensities of the $\operatorname{Tan}(\delta)_{\varepsilon}$ decreased with the decrease of the surface layer thickness. The increase of the glass transition temperature was explained by Lipatov (1977) to indicate a restriction of the main chain mobility in the layers of the polymer close to the vicinity of the filler surface, while he explained the decrease in the intensities to indicate of the involvement of fewer chains in the relaxation. This observation can be explained by the stiffness of the interfacial region resulting from the existence of strong linkages between the silica and the polymer and/or due to

\begin{tabular}{|c|c|c|c|c|}
\hline \multirow[b]{3}{*}{ ABTE amount } & \multicolumn{4}{|c|}{ Average maximum peak temperature $\left({ }^{\circ} \mathrm{C}\right)$} \\
\hline & \multicolumn{2}{|l|}{$\alpha$-Relaxation } & \multicolumn{2}{|l|}{$\beta$-Relaxation } \\
\hline & $10 \cdot 0 \mathrm{kHz}$ & $33 \cdot 3 \mathrm{kHz}$ & $0 \cdot 252 \mathrm{kHz}$ & $1.0 \mathrm{kHz}$ \\
\hline 0 & $166 \cdot 4 \pm 0 \cdot 5$ & $175 \cdot 0 \pm 0 \cdot 5$ & $-69 \cdot 1 \pm 4 \cdot 2$ & $-43 \cdot 3 \pm 0 \cdot 9$ \\
\hline $3 \times$ & $155 \cdot 0 \pm 3 \cdot 2$ & $159 \cdot 4 \pm 1 \cdot 7$ & $-63 \cdot 6 \pm 1 \cdot 8$ & $-50 \cdot 7 \pm 2 \cdot 3$ \\
\hline $30 \times$ & - & - & $-70 \cdot 0 \pm 3 \cdot 1$ & $-62 \cdot 5 \pm 1 \cdot 6$ \\
\hline
\end{tabular}

(C) 2000 Blackwell Science Ltd, Journal of Oral Rehabilitation 27; 250-268
Table 6. Average maximum peaks temperatures $\left({ }^{\circ} \mathrm{C}\right)$ from $\operatorname{Tan}(\delta)_{\varepsilon}$ measurements for different amounts of ABTE treatment of $75 \mathrm{wt}$ \% zirconia-silica dispersed in UDMA for $\alpha$-relaxations at 10.0 and $33.3 \mathrm{kHz}$ and for $\beta$-relaxations at 0.252 and $1 \cdot 0 \mathrm{kHz}$ 

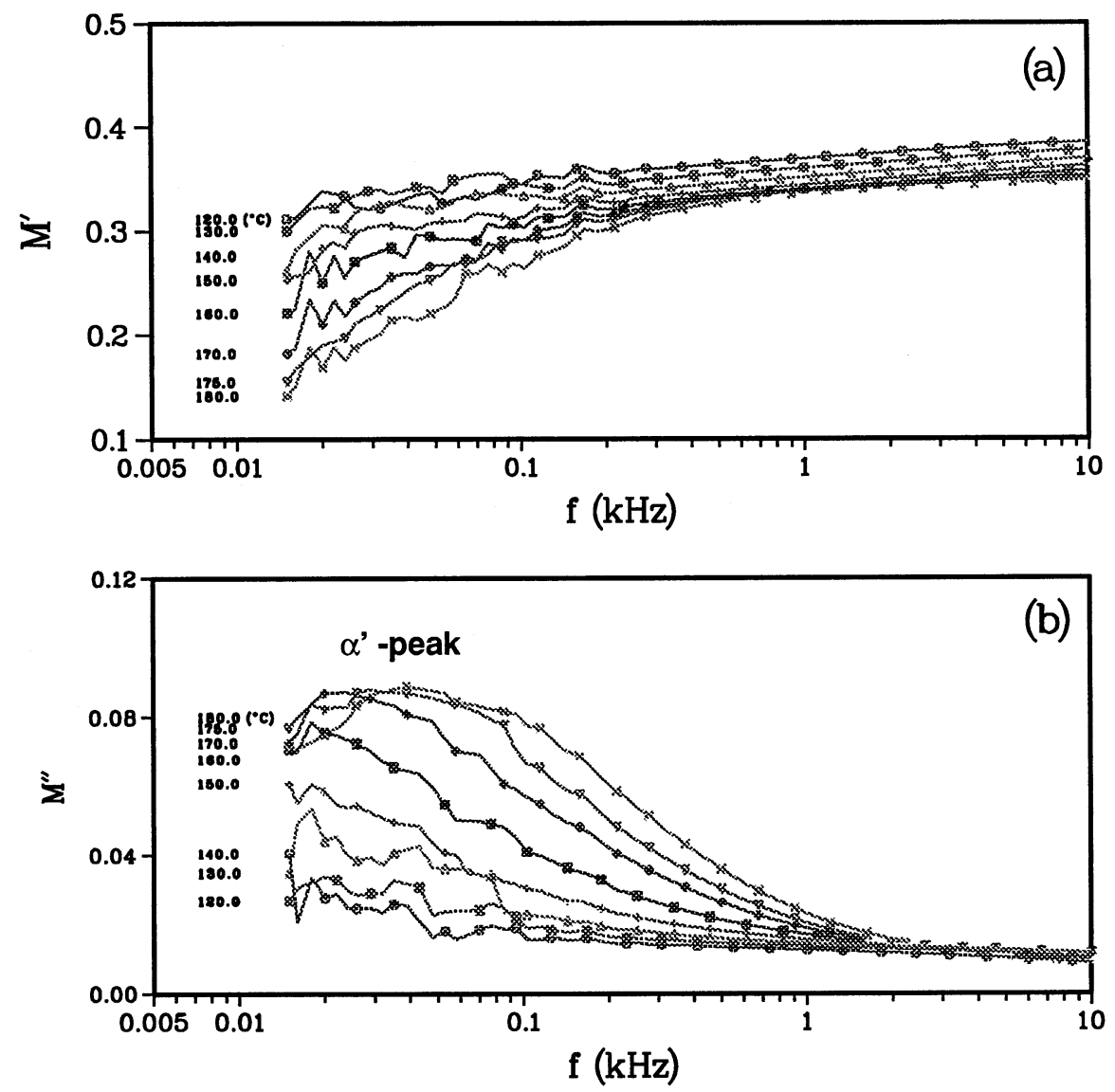

Fig. 9. The spectra of (a) $M^{\prime}$ and (b) $M^{\prime \prime}$ vs. frequency for $\alpha^{\prime}$-relaxation of $3 \times$ ABTE-treated zirconia-silica-filled UDMA over the temperature range $120-180^{\circ} \mathrm{C}$ and over the frequency range $0 \cdot 01-10 \mathrm{kHz}$.

changes in conformation of the surface layer at the interface. If the restriction of the mobility occurred only in the surface in direct contact with the filler, one cannot observe a change in the $T_{\mathrm{g}}$, because the amount of layer in direct contact with the filler and its mobility is very small compared with the bulk. This supports that the filler not only affected the polymer layer in direct contact with it, but also the more remote layers. Lipatov (1977) argued that the glass transition is a cooperative process, and for this reason restriction of mobility caused by the presence of the filler applies to both molecules bound to the surface and molecules bonded into aggregates and other superstructures. So, the increase in the $T_{\mathrm{g}}$ in the presence of the filler is a result of the restriction of the mobility of the chains close to the surface, which in turn restricts the mobility of other chains in the aggregates. However, in the filled polymer, the presence of a separate transition that characterize the interface due to the surface layer or to interfacial polarization was not observed. One reason for not observing the separate transition was explained by Lipatov (1977) to be a result of low filler's content and the difference between the transition temperature of the surface and that of the bulk is insignificant, so that both transitions appear as one transition shifted to a higher temperature. Another reason for not observing the separate transition was explained by Smyth (1955), to be a result of insignificant difference between the dielectric constants and conductivities of both the polymer and the filler which is a requirement for detecting the interfacial polarization.

The increase in the $T_{\mathrm{g}}$ indicates a considerable chain stiffness, which is caused by the existence of conformation restrictions, energetic interactions, or both. The conformational restriction is caused by the entropic factors in the boundary layer, while the energetic interaction is caused by the formation of additional bonds between the silica and the polymer at the interface. To evaluate the contribution of these factors on the change of the molecular motion at the interface, the dependencies of $\Delta H$ and $\Delta S$ on the increase of filler concentration, i.e. the decrease in the thickness of the 
surface layer, were looked at in more depth (Table 4). For instance, a considerable increase in the activation entropy changes of the surface layer as compared with the bulk has been observed for the main chain relaxation ( $\alpha$-relaxation). The increase in $\Delta S$ indicates that the entropy is an important factor in changing the properties of the polymer and their molecular mobility in the surface layer. Fabulyak \& Lipatov (1973) and Lipatov (1977) explained this increase of the activation entropy as a result of the requirement of greater conformational changes in the case of stiff chains than of flexible ones for the transition of molecular segments from one position to another during the relaxation. In addition, the activation energy values were increased
Fig. 10. The spectra of (a) $M^{\prime}$ and (b) $M^{\prime \prime}$ vs. frequency for $\alpha^{\prime}$-relaxation of $30 \times$ ABTE-treated zirconia-silica-filled UDMA over the temperature range $120-180^{\circ} \mathrm{C}$ and over the frequency range $0 \cdot 01-100 \mathrm{kHz}$.
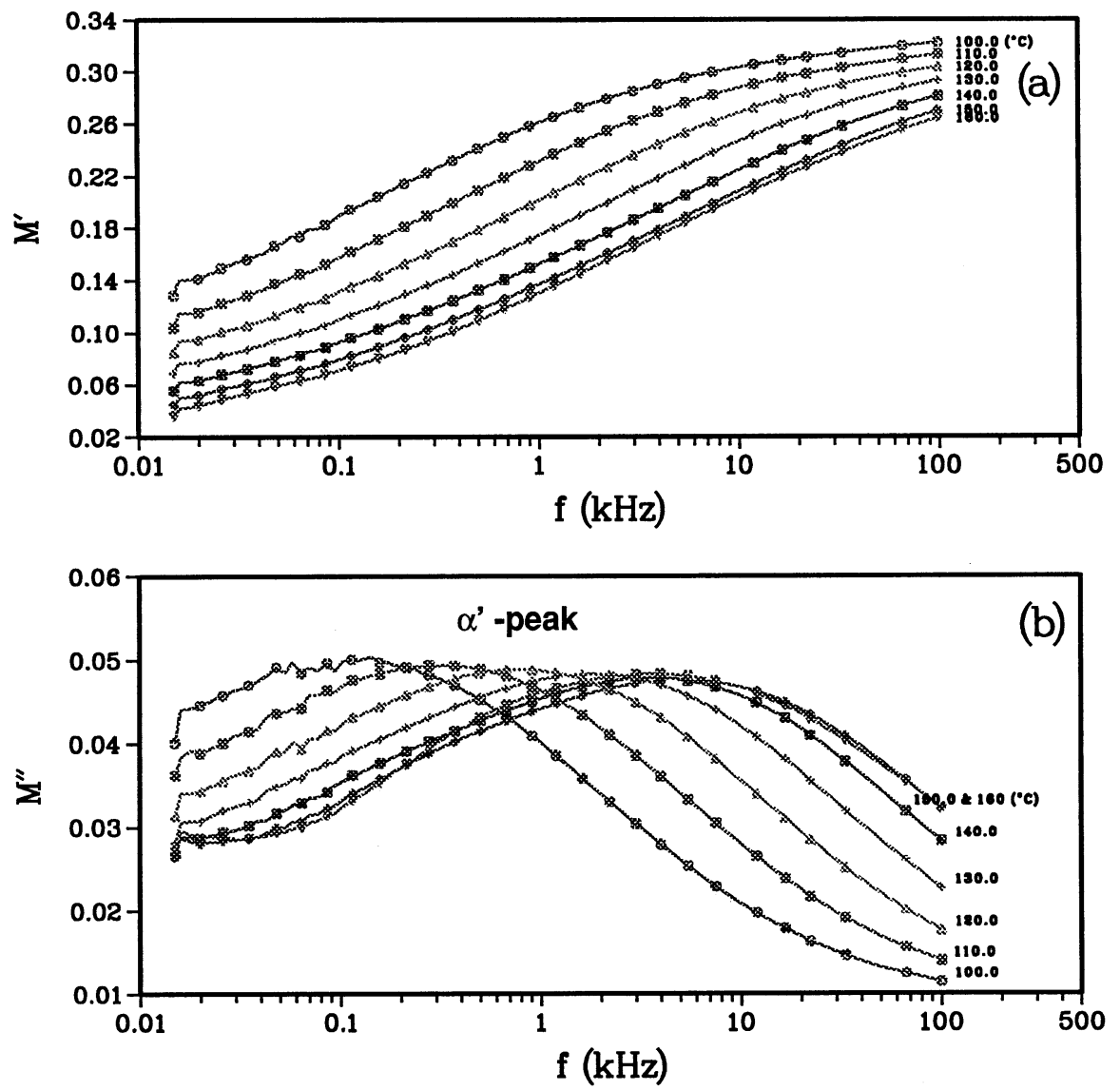

Table 7. Activation energies $(\Delta H)$ from $\operatorname{Tan}(\delta)_{\varepsilon}$ measurements, half-width of bands $\left(\Delta_{1 / 2}\right)$ for $\alpha$ - and $\beta$-relaxations at 120 and $10^{\circ} \mathrm{C}$, respectively, intensities $(\lambda)$ of $\operatorname{Tan}(\delta)_{\varepsilon}$ at $10.0 \mathrm{kHz}$ and dielectric increments $(\Delta \epsilon)$ for $\alpha$ - and $\beta$-relaxations at 180 and $-30^{\circ} \mathrm{C}$, respectively, as a function of increasing MAPM concentration in treating $75 \mathrm{wt}$ \% zirconia-silica dispersed in UDMA

\begin{tabular}{|c|c|c|c|c|c|c|c|c|}
\hline \multirow[b]{2}{*}{$\begin{array}{l}\text { MAPM } \\
\text { amount }\end{array}$} & \multicolumn{4}{|c|}{$\alpha$-Relaxation } & \multicolumn{4}{|c|}{$\beta$-relaxation } \\
\hline & $\begin{array}{l}\Delta H \\
(\mathrm{kcal} / \mathrm{mol})\end{array}$ & $\Delta_{1 / 2}($ decades $)$ & $\lambda(10 \cdot 0 \mathrm{kHz})$ & $\Delta \epsilon\left(180^{\circ} \mathrm{C}\right)$ & $\begin{array}{l}\Delta H \\
(\mathrm{kcal} / \mathrm{mol})\end{array}$ & $\Delta_{1 / 2}($ decades $)$ & $\lambda(0 \cdot 252 \mathrm{kHz})$ & $\Delta \epsilon\left(-30^{\circ} \mathrm{C}\right)$ \\
\hline 0 & $49 \cdot 9 \pm 0 \cdot 6$ & $4 \cdot 95$ & 0.016 & $0 \cdot 85$ & $6 \cdot 7 \pm 0 \cdot 2$ & $5 \cdot 49$ & $0 \cdot 0024$ & 0.0098 \\
\hline $1 \times$ & $57 \cdot 2 \pm 2 \cdot 5$ & $5 \cdot 25$ & 0.019 & 0.49 & $7 \cdot 7 \pm 0 \cdot 4$ & $4 \cdot 69$ & 0.0027 & 0.0260 \\
\hline $3 \times$ & $48 \cdot 5 \pm 1 \cdot 6$ & $4 \cdot 17$ & 0.015 & 0.49 & $10 \cdot 5 \pm 1 \cdot 2$ & $4 \cdot 24$ & 0.0019 & 0.0094 \\
\hline $6 \times$ & $41 \cdot 8 \pm 2 \cdot 7$ & $3 \cdot 73$ & $0 \cdot 012$ & $0 \cdot 77$ & $11 \cdot 3 \pm 0 \cdot 6$ & $4 \cdot 89$ & $0 \cdot 0027$ & $0 \cdot 0135$ \\
\hline $10 \times$ & $43 \cdot 6 \pm 6 \cdot 4$ & $3 \cdot 82$ & $0 \cdot 023$ & 0.65 & $7 \cdot 5 \pm 0 \cdot 2$ & $5 \cdot 01$ & $0 \cdot 0027$ & $0 \cdot 0104$ \\
\hline $30 \times$ & $42 \cdot 3 \pm 0 \cdot 8$ & $5 \cdot 65$ & 0.019 & 0.93 & $8 \cdot 6 \pm 0 \cdot 4$ & $5 \cdot 04$ & $0 \cdot 0027$ & 0.0173 \\
\hline
\end{tabular}


Table 8. Activation energies $(\Delta H)$, activation entropies $(\Delta S)$ for $\alpha$-and $\beta$-dielectric relaxation processes at 432 and $232 \mathrm{~K}$, respectively, intensities $(\lambda)$ of $\operatorname{Tan}(\delta)_{\varepsilon}$ at $10 \cdot 0 \mathrm{kHz}$ and dielectric increments $(\Delta \epsilon)$ for $\alpha$ - and $\beta$-relaxations at 160 and $-30{ }^{\circ} \mathrm{C}$, respectively, as a function of increasing ABTE concentration in treating $75 \mathrm{wt} \%$ zirconia-silica dispersed in UDMA

\begin{tabular}{|c|c|c|c|c|c|c|c|c|}
\hline \multirow[b]{2}{*}{$\begin{array}{l}\text { ABTE } \\
\text { amount }\end{array}$} & \multicolumn{4}{|c|}{$\alpha$-Relaxation } & \multicolumn{4}{|l|}{$\beta$-Relaxation } \\
\hline & $\begin{array}{l}\Delta H \\
(\mathrm{kcal} / \mathrm{mol})\end{array}$ & $\begin{array}{l}\Delta S \\
(\mathrm{kcal} / \mathrm{mol} \mathrm{K})\end{array}$ & $\lambda(10 \cdot 0 \mathrm{kHz})$ & $\Delta \epsilon\left(160^{\circ} \mathrm{C}\right)$ & $\Delta H(\mathrm{kcal} / \mathrm{mol})$ & $\begin{array}{l}\Delta S \\
(\mathrm{kcal} / \mathrm{mol} \mathrm{K})\end{array}$ & $\lambda(0.252 \mathrm{kHz})$ & $\Delta \epsilon\left(-30^{\circ} \mathrm{C}\right)$ \\
\hline 0 & $49 \cdot 9 \pm 0 \cdot 6$ & $0 \cdot 184$ & 0.016 & $0 \cdot 34$ & $6 \cdot 7 \pm 0 \cdot 2$ & $0 \cdot 105$ & 0.0024 & 0.0098 \\
\hline $3 \times$ & $46 \cdot 1 \pm 0 \cdot 2$ & $0 \cdot 143$ & 0.033 & $1 \cdot 87$ & $9 \cdot 0 \pm 0.3$ & $0 \cdot 116$ & 0.0035 & 0.0071 \\
\hline $30 \times$ & - & - & - & $23 \cdot 87$ & $8 \cdot 9 \pm 0 \cdot 1$ & $0 \cdot 117$ & $0 \cdot 0040$ & 0.0048 \\
\hline
\end{tabular}

as a function of the increase in filler concentration, while the pre-exponential factor values decreased. Such an increase is an indication of the decrease in the main chain mobility due to the increase in the chain rigidity with the increase in filler concentration. Fabulyak \& Lipatov (1973) showed an increase of the activation energy values of the oligomer as the flexibility of its molecular chain decreases. Thus, the filler functions as a cross-linking agent that restricts the polymer motion by adsorption of the polymer onto its surface and is reflected as an increase in the activation energy values. On the contrary, Lipatov (1977) explained the reduction of the pre-exponential factor values in the presence of the hard particles due to reduction of the density of packing in the surface layer, and an increase in the free volume.

The decrease in the intensity of $\operatorname{Tan}(\delta)_{\varepsilon}$ might be caused by the decrease of the concentration of the polymer, which in turn reduces the concentration of the polar groups. However, it might further support that the filler acts as a cross-linking agent that causes a decrease in the motion of the polar groups, which is manifested by the decrease in the $\operatorname{Tan}(\delta)_{\varepsilon}$ intensities.

In summary, the incorporation of the filler causes the polymer to adsorb onto the surface of the filler to create a thin layer with different thicknesses depending on the amount of the filler concentration. This layer has different properties than those of the bulk, which are reflected by the entire relaxation behaviour of the composites. In the layer close to the filler and in the remote layers, the restriction of the chain mobility is a result of conformational restrictions imposed by the surface that lowered the chain flexibility. These effects dominate the reduction of the density of packing and other factors, and all these factors are reflected by an increase of the $\alpha$-relaxation towards higher temperatures.
The effect of the filler on the $\beta$-relaxation. The $\beta$-peak corresponds to the side group relaxation ( $\beta$-relaxation) of the polymer and is shifted to lower temperatures with the increase in the filler concentration. This indicates an increase in the mobility of the side groups at the interface, which is due to the reduction of the density of packing. To support this statement, Lipatov \& Sergeeva (1974) showed only portions of the chains are directly bonded to the surface, while the rest remain free. In addition, the activation energy values decreased with the presence of filler in the low-relaxation region, which supports the explanation of the free movement of molecules caused by the reduction of the density of packing in the boundary layer. These results show that the energetic factors are insignificant.
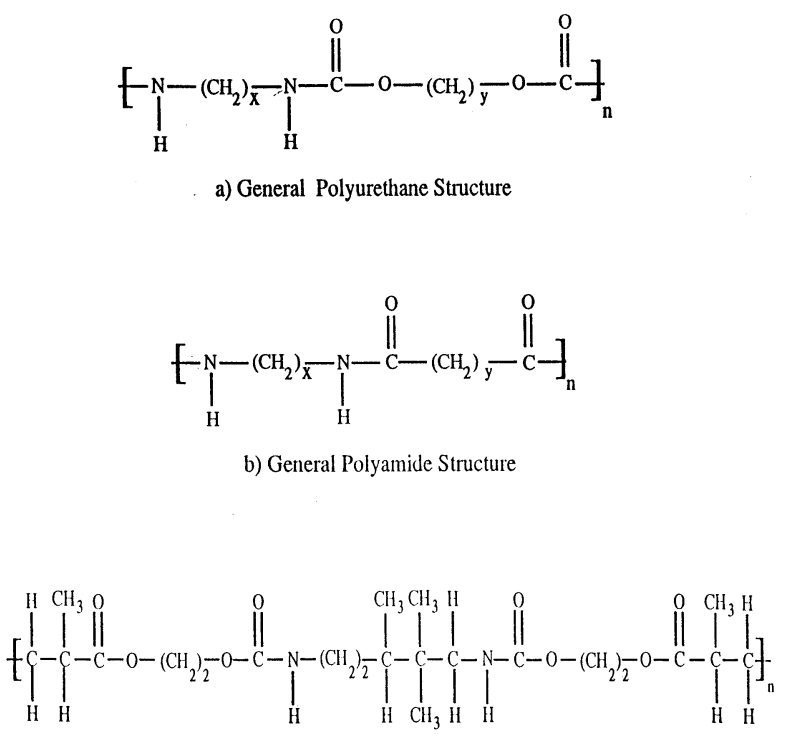

c) 2-Methyl-2-Propenoic Acid (2, 4, 4-trimethyl-1, 6-hexanediyl) bis(imino carbonyloxy - 2, 1-ethanediyl) ester (UDMA)

Fig. 11. Structural formulae for (a) polyurethanes, (b) polyamides and (c) UDMA. 
Otherwise, one will observe indications of the restriction of the mobility of the side groups due to the formation of the additional bonds between the silica and the polymer at the interface. Further, the activation entropy showed insignificant changes and decreased to lower values, indicating that the conformational changes also do not play a major role in the conformations of the $\beta$-relaxation. As a result, the formation of large numbers of relaxants, the broadening of the $\beta$-relaxation, and the increase in the mobility of functional groups of the chains and of small units that are not bound to the surface, further supports the above statement.

The effect of silanation of filler on the dielectric relaxations of UDMA

The effect of the silane on the $\alpha$-relaxation. Since Lipatov $\delta$ Fabulyak (1972) postulated that the nature of the interface is independent of the chemical nature of the surface unless there is a specific interaction between the filler surface and the matrix, the above results show a dependence of the interface on the chemical nature of the silanated filler. For instance, when the matrix was reinforced with zirconia-silica treated with MAPM at the minimum uniform coverage of the silane, the $\alpha$-relaxation shifted to higher temperatures; however, at the higher MAPM concentrations, the $\alpha$ relaxation shifted to lower temperatures. The increase of the peak's maxima to higher temperature is indicative of the decrease of the main chain mobility in the vicinity of the filler surface. This effect can be explained by the stiffness of the interfacial region due to the existence of strong linkages between the silane and the filler, and between the silane and the matrix. One may assume that, at the low concentration of MAPM, the contributions of the chemical interactions between the zirconia-silica and the silane and between the silane and the resin dominate and are reflected as increases in the $\alpha$-relaxation temperatures. This conclusion is further supported by the increase of $\Delta \mathrm{H}$ values from $49.9 \mathrm{kcal} / \mathrm{mol}$ for the unsilanated zirconiafilled UDMA to $57 \cdot 2 \mathrm{kcal} / \mathrm{mol}$ for the MAPM-silanated zirconia-filled UDMA. Further, it has been shown by Plueddemann (1982) that the amount of silanes deposited on the mineral surfaces from an aqueous solution increases rapidly as the concentration increases to a certain transition concentration, and above this con- centration the silane increases more slowly. The transition concentration that was given by Plueddemann for MAPM is $0.4 \mathrm{wt} . \%$, which is equivalent to the minimum uniform coverage $(1 \times)$, which is given by Equation (1).

The fact that there was no indication of a new peak above the transition concentration implies the non-existence of a separate phase due to space charge separation that characterizes an interface. This proves that MAPM is a compatible plasticizer to the UDMA system. Such compatibility manifested itself in the shift of the $\alpha$-relaxations towards lower temperatures as well as the decrease of the activation energy values. These results supported the positive determination of plasticizer efficiency given by Hedvig (1977), which showed increases in the main chain mobility and in the free volume of the polymer. In addition, the increase in the $\Delta_{1 / 2}$ values implied broadening in the $\alpha$-relaxations by increasing MAPM concentration, indicating wider distribution of relaxation times. Also, $\lambda$ and $\Delta \varepsilon$ showed a general increase in their values which indicates ease of polar groups mobility in the polymer. This ease of mobility developed by attaching the MAPM molecules strongly enough to the chains of the polymer so as to contribute to the polarization involved in the mechanism. Such a contribution appeared as an enhancement to the strength of the polymer's dipole moment rather than appearing as separate losses.

Silanation of zirconia-silica with ABTE at $3 \times$ resulted in the same effect on the $\alpha$-relaxation of the composite. That is, the $\alpha$-peaks shifted to lower temperatures, and the activation energies and entropies decreased to lower values. These results also confirmed the above behaviour of increasing the flexibility of the adsorbed layer as its thickness increases due to the increase of silane concentration in filler treatment beyond the transition concentration. However, at the low concentration of ABTE $(3 \times)$, a new peak started to emerge at very low frequencies (Fig. 9) and developed to a complete peak ( $\alpha^{\prime}$-peak) at the very high concentration $(30 \times)$ (Fig. 10). The $\alpha^{\prime}$-peak obstructed the $\alpha$-peak, which was shifted to a very low temperature and appeared as a shoulder at $70^{\circ} \mathrm{C}$. This newly emerged peak appeared at lower frequencies and disappeared at higher frequencies (above $6 \mathrm{kHz}$ ) and had an activation energy of $28.9 \mathrm{kcal} / \mathrm{mol}$. This peak was attributed to part of the silane that could not penetrate the polymer and formed a separate phase incompatible 
with it. Also, the $\lambda$ and $\Delta \varepsilon$ values showed definite increases with ABTE concentration, indicating that the effective dipole moment also has been affected.

From these results, one can gain insights into the interactions between the polymer and the silane. It seems that in the presence of a compatible silane, the composite exhibited a single glass transition dispersion in the dielectric spectra, while in the presence of an incompatible silane, a new dispersion transition was separately observed. This new relaxation characterizes the inter-phase. In the presence of the compatible silane, the mechanism of its effect on the composite behaviour depends on its concentration at the interface. For instance, with small amounts of the silane, specific molecular interactions occurred between the filler surface and the matrix, which caused a restriction in the motion of the surface layer. These molecular interactions are the result of chemical linkages between the silanetriol and the silica surface as well as the carbon double bond in the MAPM and the UDMA. In addition, with large amounts of the silane, Allen, Hansrani and Wake (1981) have shown that intermediate flexible layers started to develop in the vicinity of the filler as a result of the formation of loosely adsorbed layers composed of condensed polysiloxane with uncondensed silanetriol. However, in the presence of the incompatible silane, Borisova \& Chirkov (1973) have shown that the inter-phase that started to form is caused by the formation of solvating layers in the polymer and spontaneous aggregation of the low molecular weight compound molecules. These low molecular weight compounds are composed of mixtures of structures, where the charge separations characterizes their nature. Such structures will be discussed in the next section.

The effect of the silane on the $\beta$-relaxation. Adding small amounts of MAPM up to about three times the minimum uniform coverage restricted the mobility of the free amide groups. This was reflected by the increase in the activation energy values and the shifts of the peak maxima for the $\beta$-relaxation towards higher temperatures. Also, the $\Delta_{1 / 2}$ values decreased with increasing MAPM concentration, showing narrowing of the distribution of relaxation times. Further, narrowing of the distribution of relaxation times reflects the decrease in the different number of different environments of amide groups in the system, implying that higher amounts of free amide groups are reacted and having similar relaxation times. This seems to support the idea that a low concentration of MAPM (about $3 \times$ ) is enough to decrease the mobility of amide groups, probably by increasing the density of molecular packing at the interface between the filler and the polymer, thus decreasing the distance between the molecules and augmenting the chance of inter-chain coupling, which existed in the polymer network.

However, adding large amounts of MAPM increased the mobility of the free amide groups. This was seen by the decrease in the activation energy values and the shift of the peak maxima for the $\beta$-relaxation towards lower temperatures, along with the broadening of the relaxation times. These results imply that the increase in the amide groups mobility resulted from the reduction of inter-chain coupling by breaking of the amidehydrogen bond that exists in the polymer network and increasing the segmental mobility by dilution. This breaking is a result of the MAPM molecule, through unreacted silanetriols that might replace the amidehydrogen bonds. These unreacted silanetriols are attached strongly enough to the amide groups so they move the chains as they change configuration and, hence, increase the dipole moment of the amide groups.

The $\Delta_{1 / 2}$, the activation energies and the peak maxima temperatures at 0.252 and $1.0 \mathrm{kHz}$ exhibited maxima at about $3 \times$ MAPM content. This concentration seems to be optimum with respect to the efficiency of MAPM.

The hydrolyzed aminosilane may exist in two structural forms, and they are shown in Figs 12a and b. Both structures can probably be found in equilibrium. One of these structures is an open extended form (Fig. 12a), where the amino groups exist as free $\mathrm{NH}_{2}$ or strongly hydrogen bound to the silica, while the other structure is a cyclic hydrogen-bonded amine structure (Fig. 12b), where a partial proton transfer exists $\left(\mathrm{SiO} \cdots \mathrm{H} \cdots \mathrm{NH}_{2}^{+}\right.$) in the ring structure as shown by Ishida \& Koenig (1978) and Plueddemann (1982). The open extended structure seems to predominate in the low concentrated solution, while the low molecular cyclic structures are favoured in concentrated solution as indicated by Plueddemann (1982). These two structures can be seen to influence the behaviour of the dielectric dispersions of UDMA. For instance, adding different amounts of ABTE shifted the peak maximum 


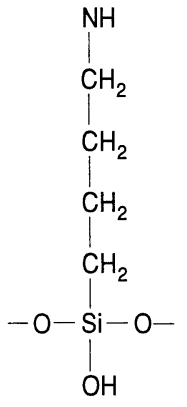

a) Open extended structure

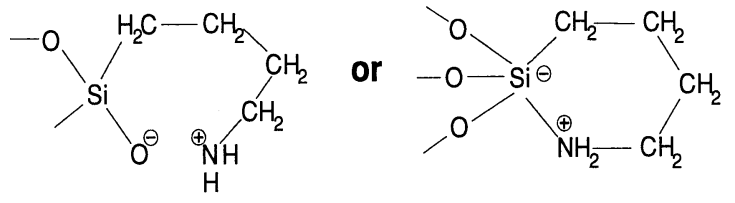

b) Cyclic structure

Fig. 12. Proposed models of amino functional silane in water: (a) open extended model and (b) cyclic model.

temperatures for the $\beta$-relaxation towards lower values and caused the new separate loss to occur. The lowering of the $\beta$-relaxation temperature indicates that the ABTE plasticized the polymer by increasing the segmental mobility and the reduction of the interchain bonding. Such inter-chain bonding occurred by replacement of the hydrogen bonding existing in the original polymer to the hydrogen bonding between the ABTE's free amino groups or the unreacted silanetriol and the amine or carbonyl groups existing in the UDMA. This seems to occur at very low concentrations of ABTE, and it is only limited to the first few monolayers of the silane. However, at the higher concentration of ABTE, the occurrence of the new peak indicates the existence of a separate inter-phase, which has space charge separations that oscillate and move with the alternating electric field and resemble the interfacial polarization. This supports the existence of the cyclic structure with a partial proton transfer formed by the aminosilane, especially at the higher concentration. Such a structure could not react or form any chemical links with the UDMA, and was forced into a separate phase. This seems to be the dominant effect on the dielectric spectra, since there is an overall increase in the intensity of the $\operatorname{Tan}(\delta)_{\varepsilon}$ values.

The activation energy values increased slightly and became independent of the ABTE concentration. Such independence indicated that ABTE contributes only slightly to this loss mechanism, and the hydrogen bonding described above occurred only at the first few monolayers and became irrelevant at higher concentrations. This was further supported by the decrease in the dielectric increment of the $\beta$-relaxation (Table 8 ), which indicated the decrease in the effective dipole moment. Such a decrease implied the restriction of the amino group motion and/or the decrease in the number of the free amide groups available, which were depleted by hydrogen bonding to the amino groups of the silane. These results further support the theory that the above assignment of the $\beta$-relaxation is indeed the result of the relaxation of the free unbounded $\mathrm{NH}_{2}$ groups in UDMA.

\section{Acknowledgments}

This investigation was supported in part by a Center Grant from USPHS, Grant P50DE09296 from the National Institute for Dental Research, National Institutes of Health, Bethesda, MD 20892, U.S.A.

\section{References}

Allen, K.W., HansRani, A.K. \& Wake, W.C. (1981) The structure and properties of films of siloxane coupling agents. Journal of Adhesion, 12, 199.

Arkles, B. (1987) Silane Coupling Agent Chemistry. Petrarch Systems Catalogue, Bristol, PA.

BAKer, W.O. \& YAger, W.A. (1942) Dielectric loss in nylon 610. Journal of American Chemical Society, 64, 2171.

Borisova, T.I. \& CHIRKOv, V.N. (1973) The mechanism of the low temperature dielectric relaxation of polymers containing low molecular weight impurities. Vysokomol Soyed, A15(10), 2304.

Boyd, R.H. (1959) Dielectric loss in 66 nylon (polyhexamethylene adipamide). Journal of Chemistry and Physics, 30(5), 1276.

Douglas, W.H., Craig, R.G. \& Chen, C.C. (1979) A new composite restorative based on a hydrophobic matrix. Journal of Dental Research, 58(10), 1981.

FABUlyak, F.Y. \& LipATOV, Y.S. (1973) Nuclear magnetic relaxation of different types of oligomers in the bulk and in the boundary. Vysokomol Soyed, A15(7), 1513.

Gordon, J., Howard, G. \& Shanks, R.A. (1982) The influence of filler particles on the mobility of polymer molecules. Journal of Macromolecules Science-Chemistry, A17(2), 287.

Hedvig, P. (1977) Dielectric Spectroscopy of Polymers. John Wiley \& Sons, New York.

IshidA, H. \& Koenig, J.L. (1978) The reinforcement mechanism of fiber-glass reinforced plastics under wet conditions: a review. Polymer Engineering $\theta$ Science, 18(2), 128. 
LiPATOV, Y.S. (1977) Relaxation and viscoelastic properties of heterogeneous polymeric composition. In: Advances in Polymer Science, vol. 22, 1. Springer, New York.

Lipatov, Y.S. \& Fabulyak, F.Y. (1972) Relaxation processes in the surface layers of polymer at the interface. Journal of Applied Polymer Science, 16, 2131.

Lipatov, Y. \& Sergeeva, L. (1974) Adsorption of Polymers. John Wiley $\&$ Sons, New York.

McCrum, N.G., Read, B.E. \& William, G. (1967) Anelastic and Dielectric Effects in Polymeric Solids. John Wiley \& Sons, New York.

Mohsen, N.M. \& CRAIG, R.G. (1995) Effect of silanation of filler on their dispersibility by monomer systems. Journal of Oral Rehabilitation, 22, 183.

Moynihan, C.T., Boesch, L.P. \& LABerge, N.L. (1973) Decay function for the electric field relaxation in vitreous ionic conductors. Physical Chemistry of Glasses, 14(6), 122.

Peyser, P. \& BASCOM, W.D. (1977) Effect of filler and cooling rate on the glass transition of polymers. Journal of Macromolecules Science-Physics, B13(4), 597.
Plueddemann, E.P. (1982) Silane Coupling Agent. Plenum Press, New York.

Sмyтн, C. (1955) Dielectric Behavior and Structure. McGraw-Hill Book Company, New York.

WADHWA, L.H. \& WALSH, W.K. (1982) Morphology and mechanical properties of radiation-polymerized urethane acrylates. I. Pure oligomers. Journal of Applied Polymer Science, 27, 591.

Whiting, R. \& JAcobsen, P.H. (1980) Dynamic mechanical properties of resin-based filling materials. Journal of Dental Research, 59(1), 55 .

Woodward, A.E., Sauer, J.A., Deeley, C.W. \& Kline, D.E. (1957) The dynamic mechanical behavior of some nylons. Journal of Colloid Science, 12, 363.

ZiEgel, K.D. \& Romanov, A. (1973) Modulus reinforcement in elastomer composites. I. Inorganic Fillers. Journal of Applied Polymer Science, 17, 1119.

Correspondence to: Dr Robert Craig, School of Dentistry, The University of Michigan, 1011 N. University Avenue, Ann Arbor, MI 48109-1078, U.S.A. 